\title{
Visual Servicescape Aesthetics and Consumer Response: A Holistic Model
}

\section{Introduction}

Aesthetics have been an important area of research in marketing for the past four decades. Interestingly, while marketing practitioners have recognized the need to consider aesthetic aspects across a wide variety of areas like product design, store interiors, mall environments, advertisement layouts, etc., the theoretical front is largely dominated by research on visual aesthetics related to physical goods (e.g., Leder and Carbon, 2005; Veryzer and Hutchinson, 1998). Research related to the aesthetic aspects in services in the form of various servicescapes and other components of physical evidence remains under-appreciated (Hightower et al., 2002; Turley and Milliman, 2000; Mari and Poggesi, 2013). Servicescapes, as part of the services marketing mix, are considered to be crucial in differentiating the service offer (Bitner, 1990), yet very little is known about the impact of the aesthetic aspects on the consumption experience (Ballantine et al., 2010; Kumar et al., 2013).

Although the aesthetics deal with visual, aural, olfactory, and tactile stimuli (Vilnai-Yavetz and Rafaeli, 2006), the visual stimulus is considered to be the most dominant aspect in servicescapes (Orth and Wirtz, 2014). Visual attributes have been found to have more influence on how consumers evaluate services (Orth and Crouch, 2014; Orth et al., 2012). Further, the inferences about other sensory experiences are often based on visual appearance (Bloch et al., 2003), and the images that form consumer experiences mostly flow from visual and, to a lesser extent, from other senses (Prahalad and Sawhney, 2011). Following Vacker's (1993) framework for classifying visual beauty into two groups, namely subjective (Aristotle's theory of beauty) and objective (Plato's and Kant's theories of beauty), marketing 
literature on visual aesthetics may be categorized into theories that treat aesthetics as subjective and objective. Subjectivity refers to personal psychological states - one's own way of feeling or perceiving, which changes according to the changing environment (Addis and Holbrook, 2001); while the objective approach suggests that each object will have an ideal form which, once attained, will tend to be considered attractive by everyone (Crilly et al., 2004). However, studies have shown that aesthetic appraisals are not often based solely on geometric or physical features (Gifford et al., 2000) and, hence, a pure evaluation on an objective basis may not provide a realistic picture. Also, objective attributes that are assumed to be invariant across consumers are not appropriate for appraising aesthetic products (Hirschman, 1983). Moreover, in the studies conducted so far, little attention has been paid to the role of consumers in determining their own aesthetic responses (Abubakar, 2010; Booms and Bitner, 1982; Hightower et al. 2002; Raajpoot et al., 2008).

Yet, an examination of past studies, including the most seminal ones, on the visual aesthetics of servicescapes suggests that extant literature in marketing overwhelmingly adopts an objective perspective of visual aesthetics (Kumar et al., 2013). For instance, Kotler's (1973) work on atmospherics was one of the first studies to conceptualize visual aesthetic dimensions. However, later studies (e.g., Donovan and Rossiter, 1982) criticize these dimensions for not being very robust and for not having any measurable properties for aesthetic stimuli or response variables. Baker (1986) developed another set of dimensions and although they were considered to be comprehensive and popular (Grayson and McNeill, 2009; Turley and Milliman, 2000), they remained objective in nature and without empirical validation (Wagner, 2000). Bitner's (1992) conceptual framework is widely applied in studies (e.g. Abubakar, 2002; Hightower et al., 2002; Raajpoot et al., 2008; Turley and Milliman, 
2000), but this model has not been tested holistically (Ballantine et al., 2010; Godey et al., 2009). Turley and Milliman's (2000) work simply an extends Bitner's (1992) framework by adding a few additional objective dimensions. Even Wagner's (2000) model on aesthetic value has not been empirically verified. In general, the visual aesthetic aspects for servicescapes, from a subjective perspective, are under-appreciated.

In summary, it is evident that in marketing literature, little attention is paid to understand the perspective of consumers in determining their own experiences, which is a subjective transformation of the various features present in a servicescape. The beauty of a servicescape not only depends on the individual objects seen by the consumers but also on how they make an impact through an arrangement in the space. The prevailing view in modern aesthetics appreciation of visual aesthetics of the servicescape thus depends on the combined effects of all the elements present in the environment which, in turn, can be better captured in a subjective approach focused on the viewer's experience of the environment (Tveit et al., 2006).

Against this background, the purpose of this study is to move beyond extant research by: (1) developing a model for appraising visual servicescape aesthetics from the consumer perspective. Borrowing from evolved science in landscape studies, we conceptualize a model with visual servicescape aesthetic stimuli that are holistic and subjective thus bringing in the consumer's evaluation rather than the designer's evaluation and how they influence affective responses and preferences; and (2) testing the moderating role of service contexts (i.e., hedonic versus utilitarian service context) of consumers' affective responses. 


\section{Conceptual framework}

In many ways, servicescapes share similarities with landscapes - apart from the elements distributed in a three-dimensional space in both cases, both of them provide visual cues like spatial patterns, massing of elements, pathways, and unique features to assist viewers' comprehension. Studies in architecture and interior design have determined that, like landscapes, built environments and urban scenes also provide information cues to satisfy individuals' need for understanding and exploration (e.g., Akbar et al., 2011; Dogu and Erkip, 2000; Scott, 1993). Hence, servicescape aesthetic evaluation from the consumer perspective using theories in environmental psychology offers a significant advance in the science of design of spaces where a consumer is served.

Environmental psychology deals with the effect of the environment on human behavior and numerous studies (e.g. Ikemi, 2005; Palmer, 2000; Stamps, 2004) related to the visual aesthetic aspects of the environment deal with this domain. Berlyne's (1972) experimental aesthetics studies have been the most influential and dominant in the field of environmental psychology (Martindale et al., 1990) which suggests that preference for any stimulus will be determined by its psychophysical, ecological, and collative properties. Two environmental psychology models based on collative variables and evolved from Berlyne's (1951) works, namely, Kaplan’s (1987) information-processing model and Mehrabian and Russell's (1974) S-O-R model (subsequently modified by Russell and Pratt (1980)) are used in this study to develop a theoretical framework (Figure 1 below) for evaluating visual servicescape aesthetics. 
"Insert Figure 1 about here"

Kaplan's (1987) information-processing model is one of the most significant theories in landscape visual preference research (e.g. Cheng, 2007; Hagerhall, 2001; Stamps, 2004) and is proven to be well suited in the study of aesthetic attributes (Eckman and Wagner, 1994). Based on the structural properties of landscapes, it postulates that people approach an environment with two basic needs: (a) to understand; and (b) to explore. The information in the environment may be immediately perceivable in the two-dimensional plane or may be inferred as perceivable if one moves deeper into the three-dimensional environment (Kaplan, 1987). Crossing these needs with the availability of information, a comprehensive set of four stimulus variables is proposed, namely, coherence (immediate understanding), complexity (immediate exploration), legibility (inferred understanding), and mystery (inferred exploration) (Kaplan, 1987). Although Kaplan's environmental stimuli are popular in landscape visual preference research, they are not much applied in the built environment (Stamps, 2004). However, the four structural properties identified in Kaplan's (1987) models are also observable in servicescapes. Therefore, just as a landscape viewer makes a lot of interpretations based on information available from the spatial organization of the scene which leads to further exploration, a consumer in a servicescape can also be expected to make inferences about the services from the first look of the servicescape scene. This can lead to approach (or avoidance) behaviors (Kaplan and Kaplan, 1989). Yet, Kaplan's (1987) model is not devoid of limitations. The first major limitation is that the model lacks any measures 
for affective responses. Second, all four predictor variables from Kaplan's model are concerned only with the structural collative properties of the environment, without considering the contents (Kaplan, 1987). For servicescapes, there could also be content qualities which can contribute to preference. One such collative content property (Martindale and Moore, 1988), which is significant for servicescape, is visual newness or novelty (Roy and Tai, 2003).

To address some of the limitations of Kaplan's (1987) model, which are relevant to the context of our visual servicescape aesthetics model, we have combined it with Mehrabian and Russell's model (1974), a widely applied model in servicescape studies (e.g., Donovan and Rossiter, 1982; Bellizzi and Hite, 1992; Bitner, 1992; Baker et al., 2002; Wirtz and Bateson, 1999; Turley and Milliman, 2000). According to this model, the various environmental stimuli expressed in terms of complexity and novelty generate two basic affective states - pleasure and arousal - which then mediate preference (or lack of it) towards the environment (Donovan and Rossiter, 1982). Thus, this model has a comprehensive set of affective response variables, which are empirically validated in many studies (e.g., Donovan and Rossiter, 1982; Bellizzi and Hite, 1992). One main drawback of Mehrabian and Russell's framework is that it does not elaborate on stimuli taxonomy (Gilboa and Rafaeli, 2003), which we are adapting from Kaplan's (1987) model. It is, therefore, evident that the combination of these two models can provide a parsimonious set of (a) stimulus variables to measure visual aesthetics of servicescapes, as well as, (b) a set of variables to measure the affective responses and preferences of the consumers within a systematic framework. 


\section{Visual aesthetics and consumer responses}

Affective responses towards the target are found to strongly influence judgement and decision making (Pham et al., 2001). A consumer may perceive a servicescape to be varying in terms of the five visual aesthetics stimuli, namely, legibility, mystery, coherence, complexity, and novelty which, in turn, influence an observer's level of arousal, pleasure, and preference. Aesthetic response is defined as a preference (like-dislike) elicited by a visual encounter with an environment (Ulrich, 1983). Since the study has made use of a single preexperimental design, we have measured the affective responses (arousal and pleasure) and preferences as the aesthetic response leads to approach behavior in consumers (Ulrich, 1986).

\section{Hedonic versus utilitarian service contexts}

The service contexts - hedonic or utilitarian - may also influence consumer affective responses and preferences to visual servicescape aesthetics. Hedonic services are those that provide consumers with values such as excitement, playfulness, and entertainment; whereas, utilitarian services are those that provide consumers with functional utilities to solve practical problems or which a consumer considers as work accomplishments (Babin et al., 1994; Jiang and Wang, 2006). Consumers in hedonic service contexts actively seek arousal and pleasure aspects or "affective gratification", (Kempf, 1999), as compared to utilitarian service contexts, where they look for more instrumental utility, and hence rational approach predominates (Jiang and Wang, 2006). This distinction between hedonic and utilitarian services therefore point to the differential impacts of visual servicescape aesthetics on a consumer's affective responses and preferences. For instance, the consumer's evaluation of a hedonic service context will be based on how much affective gratification they gain - an aspect that may be absent from their evaluation of the utilitarian context. 


\section{Hypotheses}

\section{Influence of legibility}

Borrowing the term from Lynch (1960), legibility refers to the level of distinctiveness that enables viewers to understand or categorize the contents of a scene by observing the features present in the environment that facilitate understanding and way-finding (Kaplan, 1979, 1987). Legibility is an inferential aspect of comprehension (Singh et al., 2005).

Although different studies operationalize this concept in multiple ways, the most significant and commonly identified sub-dimensions that capture the dependencies of legibility are (a) clarity of layouts or the presence of signage (e.g., Bonfanti, 2013; Dogu and Erkip, 2000; Newman, 2007); (b) the presence of landmarks (Lynch, 1960; Tlauka and Wilson, 1994; Tversky, 1993; Herzog and Leverich, 2003), and (c) the presence of walkways (e.g., Farr et al., 2013; Finlay et al., 2006; Hanyu, 2000).

Extending the concept to servicescapes, legibility refers to the ease with which consumers' recognize the various elements present, and their spatial configurations, thereby facilitating and comprehending information processing and way-finding. Thus, a servicescape that is visually organized with readily identifiable features, signage or landmarks, and good interior and flooring configuration is more likely to be perceived as high on legibility.

According to information-processing theory, legibility aids people in creating a "cognitive map" - some kind of mental representation - which acts as a reference to guide them through the environment (Kaplan, 1979). Therefore, legible environments can reduce confusion and emotional discomfort for users (Wener and Kaminoff, 1983), thus improving the service consumption experience. Further, an increase in the level of legibility facilitates information processing, reduces ambiguity, and enhances quicker goal attainment, thereby 
increasing positive affective responses (Herzog and Leverich, 2003). Studies in natural settings have shown a positive linear relationship between legibility and affective responses (e.g., Hanyu, 2000). The positive effects of legibility can also be construed through the idea of 'situation normality' (McKnight and Chervany, 2001). Situational normality involves a situation that is normal, proper and customary. As McKnight and Chervany (2001, p. 6) argue, "a positive ordered setting is likely to facilitate a successful venture". A servicescape that is high in legibility will also be high in situational normality as it is properly organized and possesses readily identifiable features. Thus, a situation high in legibility could generate positive feelings. Positive affective responses are also found to be the positive predictors of preference in a natural (landscape) setting (Herzog and Kropscott, 2004). Hence, for servicescapes it is also hypothesized that:

H1: Affective responses - namely (a) arousal and (b) pleasure - mediate totally or partially the relationship between the perceived level of legibility and the preference in such a way that the greater the legibility, the greater the affective responses and the greater the preference.

Given that the services context influences a consumer's affective response, we expect noticeable differences between consumer responses in the hedonic and utilitarian service contexts. According to Kaplan (1987), legibility is an understanding variable. In utilitarian service contexts, consumers view services as more functional and task related (Batra and Ahtola, 1991; Babin et al., 1994), and so understanding of the servicescape is very important for easy services consumption. This may not be the case with hedonic contexts, where the primary focus will be on the experiential aspects of the servicescapes (Hirschman and Holbrook, 1982) and, hence, the consumer may not be concerned about the understanding aspects of the environment. Therefore, it is hypothesized that:

H1a: The perceived legibility of the servicescape bears a positive linear relationship to consumers' affective responses - namely (a) arousal and (b) pleasure - but this 
relationship will be stronger for utilitarian service contexts than for hedonic service contexts.

\section{Influence of Mystery}

Mystery theory, introduced by Lynch (1960), refers to the hidden information present in the scene (Kaplan, 1979; 1987); that is, how much more information the scene promises if one could walk deeper into it (Stamps, 2004). So, any features that encourage one to enter more deeply into the larger environment with the promise that one could gain interesting new information enhances mystery (Herzog and Kropscott, 2004). As with legibility, mystery is also inferential in nature and can be applied not only for landscapes, but also for artificial environments (Ikemi, 2005). Here, also based on the landscape literature that has explored the concept of mystery empirically, three sub-dimensions of mystery are identified: (a) lighting level, which will have an influence on the judgement of safety and enclosure effect suggesting that proper lighting promises more information than in darkness (Stamps, 2006); (b) spaciousness or depth of view which describes how far one can explore the environment, (Stamps, 2010; Palmer, 2000); and (c) visual screening or visual permeability suggesting the degree to which the view is visually obstructed (Ikemi, 2005).

For servicescapes, mystery refers to those characteristics that partially screen (hinder the view) any interesting or un-interesting features that might lie ahead with a promise of providing further information. Features like the lighting level and spaciousness of a servicescape add to the mystery. Thus, it can be argued that the higher the promise of information, the more it draws the attention of the perceiver, thus heightening the perceived mystery. According to information processing theory, the more information one acquires from the environment, the more will be the information load, which leads to emotional 
responses. So, as mystery increases, the affective responses towards the natural environment increase (Kaplan, 1987). Increased affective response leads to preference in the natural environment (Herzog and Kropscott, 2004; Nasar, 1984). Thus, it is hypothesized that:

H2: Affective responses - namely (a) arousal and (b) pleasure - mediate totally or partially the relationship between the perceived level of mystery and preference in such a way that the greater the mystery, the greater the affective responses and the greater the preference.

Here, also, we expect that the services context will influence the relationship between the perceived mystery and affective responses. Mystery is an exploration variable (Hertzog, 2004) and exploration will add to the experiential aspects of consumption in a servicescape, and so has to be significant for hedonic context where the primary consumption motive of consumers is experiential. However, the very reason consumers visit a utilitarian servicescape is to avail themselves of the service instantly; thus they will be less interested in exploring the environment for additional information. Thus, it is hypothesized that;

H2a: The perceived mystery of the servicescape bears a positive linear relationship with consumers' affective responses - namely (a) arousal and (b) pleasure - but this relationship will be stronger from the hedonic service context than from the utilitarian service context.

\section{Influence of coherence}

Kaplan (1987) refers to coherence as how well the scene is organized or how the elements in the scene complement each other or are "hanging together" (Herzog and Leverich, 2003; Herzog and Kropscott, 2004). If the viewer is able to organize the information available in the scene into a relatively small number of portions, the scene is said to be coherent (Finlay et al., 2006). Hence, it can be understood that a more orderly setting will increase an individual's ability to understand the environment (Rosen and Purinton, 2004). The major sub-dimensions identified in the literature for coherence include: (a) unity 
of the visual arrangement (Nasar, 1987); and (b) patterning or visual harmony (Tveit et al., 2006).

A servicescape setting can refer to the order, and unity, of the various elements present, including their spatial arrangement. It will be perceived as how the various elements and features appear visually balanced harmoniously with their surroundings, without any deep contrast in colors, form, and shape with the background. Coherence caters to the need for making sense of the scene which is immediately available for the viewer, thus increasing the perceived visual quality (Finlay et al., 2006; Nasar, 1987). Therefore, by aiding easy comprehension, coherence leads to affective responses according to information-processing theory (Kaplan, 1987). Taking support from Nasar (1987),it can be stated that a more organized and harmonic servicescape creates positive affective responses from consumers, leading to preference.. The positive effect of coherence can also be supported through the situational normality idea where consumers can take a cue from ordered, normal settings and develop positive attitudes (Gefen et al., 2006). Thus, it is hypothesized that:

H3: Affective responses - namely (a) arousal and (b) pleasure - mediate totally or partially the relationship between the perceived level of coherence and preference in such a way that greater coherence elicits greater affective responses leading to greater preference.

Unlike the other four variables, we consider coherence as a necessary variable equally for utilitarian and hedonic contexts. Coherence refers to the immediate sense of order which is very essential for understanding any setting (Stamps, 2004; Tang, et al., 2015); it indicates the level of harmony that a scene has (Pals et al., 2014), which is essential for any setting, irrespective of servicescape type. For utilitarian environments, coherence facilitates 
understanding by decreasing entropy (Stamps, 2006), which helps consumers in locating the key aspects of the servicescape that are needed for effective utilization of the services. Also, coherence and legibility are found to be strongly co-related, as legibility can be taken as expected coherence (Hertzog, 2004). For hedonic services, too, coherence is required as some immediate understanding is needed for people to start exploring the environment. Also, for a variable that is hypothesized to be relevant only for hedonic services, complexity, with minimum levels of coherence, lead to visual richness and will mostly be preferred (Nasar, 1987), whereas complexity without coherence results in clutter or chaos (Hanyu, 2000). Hence, it is hypothesized that:

H3a: The perceived coherence of the servicescape bears a positive linear relationship with consumers' affective responses - namely (a) arousal and (b) pleasure - this relationship will be significant in both the utilitarian service context and hedonic service context.

\section{Influence of complexity}

The fourth variable chosen, complexity, is defined as how visually rich and intricate the scene appears. It refers to the information rate or how much is going into the setting (Herzog and Kropscott, 2004; Herzog and Leverich, 2003). Thus, it can be understood that as the number and type of features present in the environment increases, the complexity also increases. The key sub-dimensions of complexity that are identified in the literature include (a) visual richness of the environment and (b) a variety of elements and features present (Tveit et al., 2006). For servicescapes, complexity will be perceived as the visual richness due to the presence of various elements (of different spatial size, shape, color, directional emphasis, surface texture and pattern, lighting composition, and type) and diversity or 
intricacy of the features of the overall scene. As the number of elements present in the environment increases, the complexity also increases.

Information-processing theory suggests that complexity creates uncertainty, which elicits involvement to reduce this uncertainty (Nasar, 1987). Arousal is a measure of the information rate of an environment that increases with its complexity (Foxall and Yani-deSoriano, 2005; Russell and Pratt, 1980). Studies in the natural environment (Nasar, 1994, 1987) based on Berlyne's $(1951,1972)$ experimental studies confirm an inverted "U" relationship between individuals' perceived complexity and the level of arousal/pleasure. In a servicescape setting, complexity increases the information load of the environment and, hence, increases the affective responses of consumers. However, too many elements and features lead to clutter, which may result in an unpleasant or irritating state of mind for the consumer. Thus, an optimum level of complexity will be best suited, which can be hypothesized as:

H4: Affective responses - namely (a) arousal and (b) pleasure - mediate totally or partially the relationship between the perceived level of complexity and the preference in an inverted " $U$ " relationship such that moderate complexity elicits greater affective responses leading to a greater preference.

According to Kaplan's theory, complexity is an immediate exploration variable (Stamps, 2004). As consumers in hedonic service contexts are driven by motives such as adventure and gratification (Arnold and Reynolds, 2003), the tendency to explore the environment will be more compared with utilitarian contexts where the motive will be the accomplishment of a task. Nevertheless, as visual richness increases, affective responses also increase and the ease of understanding the environment may decrease. Hence, we hypothesize that complexity as an exploration variable will be significant from a hedonic service context, but not significant for a utilitarian context: 
H4a: The level of perceived complexity bears an inverted " $U$ " relationship with consumers' affective responses - namely (a) arousal and (b) pleasure - but this relationship will be stronger in a hedonic service context than in a utilitarian service context.

\section{Influence of novelty}

Novelty refers to the perception of the physical setting and that activities within the setting will be different from usual (Herzog et al., 2003). In other words there will be new or unfamiliar aspects present in the scene (Russell and Pratt, 1980). Unlike landscapes, in servicescapes visual newness plays a major role and hence the understanding of a servicescape novelty is important (Roy and Tai, 2003). For servicescapes, novelty refers to visual newness or atypical aspects of the scene.

As with other variables, there are many different conceptualizations available in studies (e.g., Hekkert et al., 2003; Cox and Cox, 1994). We have taken two sub-dimensions of novelty: (a) a-typicality, based on the preference for the differences model (Herzog and Stark, 2004) and (b) newness (Blythe, 1999). According to incongruity theory, people exposed to incongruent environments process more information to reduce novelty, which leads to affective responses. Therefore, under incongruent situations, novelty enhances the information uncertainty in individuals, which increases affective responses (Ikemi, 2005). The theory also suggests that a moderate level of incongruity will be more preferred, as people will avoid situations that provide a higher level of incongruity (Michon et al., 2005). Hence, it can be argued that moderately novel stimuli are mostly preferred, as people dislike stimuli that are either too novel (arousal beyond the optimal level) or very familiar (negative "tedium" response) (Cox and Cox, 1994; Spies et al., 1997). Therefore, it is hypothesized that: 
H5: Affective responses (arousal and pleasure) totally or partially mediate the relationship between the perceived level of novelty and the preference in an inverted " $U$ " relationship such that, for moderate levels of novelty, the greater affective responses elicit greater preference.

As stated above, this study has conceptualized novelty as atypical. Studies have shown that prototypical rather than atypical stimuli are processed more easily by consumers (e.g., Reber et al., 2004). For utilitarian services, some level of prototypicality will be expected by consumers as this can enhance task accomplishment. However, for hedonic consumption, novelty is attached to uniqueness of experience (Joseph-Mathews et al., 2009). Hence, it is hypothesized that:

H5a: The level of perceived novelty bears an inverted " $U$ " relationship with consumers' affective responses - namely (a) arousal and (b) pleasure - but this relationship will be stronger for hedonic service contexts than for utilitarian service contexts.

\section{Methodical approach}

This study made use of a laboratory-like setting with a single treatment, where a single group of test units was exposed to the treatment, and then the measurements were taken (Malhotra, 2007). The usage of photographs of environments is gaining popularity in servicescape studies (e.g., Booms and Bitner, 1982; Godey et al., 2009; Griffiths and Gilly, 2012), and studies have shown that color photographs will accurately reflect on-site responses (Stamps, 2004), thereby attesting to the ecological validity of this approach. Thus, photographs were used as the treatment. 


\section{Research design}

Stage 1. Pre-test for service context selection: The main aim of this stage was to identify the service contexts for the study. A pre-test was conducted among 40 participants comprising postgraduate and doctoral students from a leading management institute in India and several working executives. The respondents came from nine different services (bank, health club, hotel, upscale restaurant, fast food restaurant, hospital, spa, educational institution, shopping mall) using the hedonic/utilitarian scale - HED/UT measurement scale (Voss et al., 2003). The mean scores for each service type were calculated on each dimension (hedonic and utilitarian), and an $x-y$ plot, (as shown in Figure -2) was created following Voss et al. (2003), identifying quadrants by scale midpoints. The services (hospital and bank) falling in the low-hedonic, high-utilitarian quadrant were chosen as utilitarian services, and the services (spa and upscale restaurant) falling in the high-hedonic, low-utilitarian quadrant were chosen as hedonic services.

\footnotetext{
"Insert Figure 2 about here"
}

Stage 2. Stimuli selection: A number of stimuli images of the four chosen servicescapes were collected from multiple sources. The sources included the book series New Space (3, 4, 5, 6, 8, $9 \&$ 10), Archiworld Co.; IDEA (3 \& 4) CA Press, and 3D images of interior designs developed by several practicing architects and interior designers, together with a sample of images from $h t t p: / / w w w . h o m e-d e s i g n i n g . c o m / 2010 / 04 / 22$-inspirationalrestaurant-interior-designs, www.flickr.com and other public internet sources. Diverse 
sources were chosen to obtain images with the widest possible variation in physical interior design elements, including spatial size, shape, directional emphasis, surface texture and pattern, and lighting composition and type, among others.

A set of 100 images per context, selected from a pool of images collected for that context (total 400 images) served as the image pool for the next step. Two step image evaluation procedures were undertaken to identify the required types of images for the study. The first stage comprised image pool scrutiny involving five design experts, two practicing architects, one interior designer, and two graphic designers, who were identified by pyramiding, in which experts were asked to recommend other potential panelists. They were all assembled together to scrutinize the images. Only the images that appeared to have standing eye-level views encountered through normal experience in the settings and in a similar orientation were chosen. The presences of human elements or brand names/logos were removed. After evaluation, a set of 60 images per service type (i.e., 240 images in total) were taken to the next stage of selection.

In the second step, image sorting based on aesthetic variables, a different set of five experts evaluated the images to ensure that the different levels of independent variables chosen for the study were present in the image pool. Here, also, experts were identified using pyramiding based on their knowledge in landscape aesthetics and interior designing and who could offer judgements affirming or differing from ours. The panel included two academicians with doctoral degrees in architecture, two architects specializing in interior design, and one research scholar in landscape architecture. The experts were provided with the definitions of the five variables along with sample images of landscapes from similar exercises published in landscape studies. After this assessment, different clusters (collections 
of images scoring high, medium, and low on each of the five dimensions) were generated. In this stage, only those images, where a minimum of four out of five experts classified into a particular cluster (high, medium, or low), were included in each group ${ }^{1}$. Finally, one image from each group was randomly chosen for each level of service type, totaling 60 images in the picture pool.

Stage 3. Data collection: For data collection, it was decided to show the images on the computer screen and to collect the responses in a questionnaire booklet in English. All images, adjusted to a size of $800 \times 600$ pixels using Adobe Photoshop CS software v. 10.0, were uploaded using an access username and password to the main server of an elite management institute in India. Studies have shown that this size fits $95 \%$ of general users' computers (Roth, 2006). To control for order effect (Daniel and Boster, 1976), all images were randomized using a Java-based applet. Also, a brief description asking the respondents to imagine that they are going to visit a particular type of servicescape for a specific purpose was provided before the presentation of each image.

Data were collected from respondents in five Indian cities, Calicut, Cochin, Trivandrum, Coimbatore, and Bangalore. The respondents (68\% male and 32\% female) were all executives working in different organizations in these cities. Participants were contacted mostly at their office premises, using the snowballing technique. The responses were

${ }^{1}$ As an illustration of the expert assessment basis, a sample set of images, developed based on experts' inputs on various dimensions, are shown in Appendix 1. These images are for illustration purposes only and are not those used for the experiments. 
collected using a physical questionnaire booklet, which was provided to the respondents along with a link for viewing the images. Each participant evaluated four sets of images: one image each of the two utilitarian servicescapes (bank and hospital) and another set of the hedonic servicescapes (spa and upscale restaurant). For each image, the respondent answered one questionnaire and, therefore, answered four sets of questions. Images were shown on individual pages (of the website) to reduce the chance of any interrelationship between picture ratings (Larson and Delespaul, 1992). Of the 400 questionnaire booklets distributed, 382 questionnaire booklets were returned. A final usable set of 350 was considered for the final analysis, which included 27 questionnaire booklets with missing values. As the number was less than $10 \%$ of the total responses received, the missing values were adjusted using the individual mean method (Shrive et al., 2006). The total sample therefore included 1,400 responses (i.e. $4 \times 350$ ). The scales used are provided in Appendix 2. Since the stimulus constructs were conceived as formative (Diamantopoulos and Winklhofer, 2001) in landscape studies, they were taken 'as is' for this study as well. Further, the items show that they: (i) do not share a common theme (for example the three items on legibility look at three different issues: clarity of layout, landmarks and walkways); (ii) as a consequence the items are not interchangeable; and, (iii) adding or dropping an item could change the conceptual domain of the construct. It can also be seen that variation in the item measures can change the variation in construct. For instance, if there are fewer visible walkways, the level of legibility will be impacted but not the other way around. Thus, based on the principles of formative constructs expounded by Jarvis et al (2003) and Rossiter (2002) we can conclude that the items used for measuring the constructs are, indeed, formative in nature. The scale items were, however, adapted to fit the servicescape context. Scales were examined by the three academicians and 
two research scholars for face validity, content validity, and for understandability and answerability. After reviewing the items, the experts also concurred with the view of using formative items. This scale was also pre-tested to verify they had acceptable thresholds for reliability and validity.

\section{Manipulation Checks:}

Several tests were conducted to check whether the manipulations were effective. First, a series of ANOVA tests was undertaken to verify the mean scores of respondents assigned to high, medium and low conditions. In support of the manipulations, participant perceived levels of the five variables were significantly different $(\mathrm{p}<0.05)$ in all the three conditions (legibility: $\mathrm{M}_{\text {high }}=5.399, \mathrm{M}_{\text {medium }}=3.691, \mathrm{M}_{\text {low }}=2.517, \mathrm{~F}(2,1397)=1300.81 ;$ mystery: $\mathrm{M}$ high $=5.344, \mathrm{M}_{\text {medium }}=3.728, \mathrm{M}_{\text {low }}=2.038, \mathrm{~F}(2,1397)=1917.45 ;$ coherence: $\mathrm{M}_{\text {high }}=$ $5.578, \mathrm{M}_{\text {medium }}=3.660, \mathrm{M}_{\text {low }}=2.105, \mathrm{~F}(2,1397)=2226.17$; complexity: $\mathrm{M}_{\text {high }}=5.482, \mathrm{M}$ medium $=3.665, \mathrm{M}_{\text {low }}=2.118, \mathrm{~F}(2,1397)=2165.63$; novelty: $\mathrm{M}_{\text {high }}=5.202, \mathrm{M}_{\text {medium }}=3.837$, $\left.\mathrm{M}_{\text {low }}=2.584, \mathrm{~F}(2,1397)=1282.13\right)$. Next, to test for any significant difference in the three dependent variables - arousal, pleasure and preference among the low, medium and high group scores for all five independent variables, another series of ANOVA tests was performed. The results, as given in Table -1, indicate significant differences in responses for legibility, mystery, coherence, complexity and novelty. Again, to test whether each image had equal contribution in the analysis, a chi-square test was completed and the results (chisquare $=50.854 ; \mathrm{df}=59 ; \mathrm{p}=0.77$ ) showed that the number of evaluations for each image do not significantly depart from the expected number of 23.33 (i.e., 1,400 responses/60 images) of evaluations, indicating that each image has an approximately equal contribution to the data on which analyses were performed. Then, to test whether all images elicited different responses for all eight variables, ANOVA tests across the images of two sub-sets of hedonic 
(30 images) and utilitarian (30 images) servicescapes were completed. The results (Table -2 ) for hedonic and utilitarian services showed that each category elicited significantly different responses for all eight variables in both contexts. Also, a post-hoc test using REGWQ procedure indicated that the servicescape images elicited at least six levels of responses for utilitarian services and at least four levels of responses for hedonic services. Finally, a Pearson chi-square test showed that different servicescape images were equally assigned to male and female participants (Pearson chi-square $=42.953, \mathrm{df}=59 ; \mathrm{p}=0.942$ ).

\section{Analysis}

The participants ranged in age from $19-54$ years, and more than $85 \%$ were between the ages of 18 and 34 years. Relatively, more of the respondents were male (68.3\%) than female $(31.7 \%)$.

To test the hypotheses, we applied the partial least square (PLS), a causal modelling approach which aims at maximizing the explained variance of the dependent variables (Hair et al., 2011) using WarpPLS 3.0, a non-linear variance-based structural equation modelling software tool that uses the PLS regression algorithm. Extant SEM software is restricted only to the linear relationships analysis (Kock, 2012); hence, we used WarpPLS3.0, which has the provision to analyze non-linear relationships. We completed two different sets of analysis. For hypotheses $H 1$ through $H 5$, we undertook the first SEM (referred to as the base model). For hypotheses $H I a$ through $H 5 a$, to test the moderating role of service contexts, we completed multi-group analysis by running two separate models for hedonic and utilitarian services. 
In the proposed base model, there are five formative variables (legibility, mystery, coherence, complexity, and novelty) and three reflective variables (arousal, pleasure, and preference). The measurement model for latent variables with reflective indicators is assessed by looking at the individual item reliability, composite reliability, convergent validity, and discriminant validity (Hair et al., 2011; Ringle et al., 2010). The indicator loadings established discriminant validity. Table 3 reports the composite reliability measures and Cronbach's alpha values for all reflective variables, which has acceptable values. The multicollinearity for the formative constructs was assessed by considering the variance inflation factors. Table 3 also reports multicollenearity statistics for the formative constructs.

"Insert Table 3 about here"

Table 4 provides the correlation coefficients and square root of AVEs of the variables.

"Insert Tables 4 about here"

A bootstrapping procedure with 999 resamples was used to generate the $t$-values for the structural paths. The path analysis model is given in Figure 3.

"Insert figure 3 about here" 
For the overall goodness of fit for the model, the GoF measure devised by Tenenhaus et al. (2005) was used. Wetzels et al. (2009) propose the following thresholds for GoF: small $=0.1$, medium $=0.25$, and large $=0.36$. Alternatively, the model is also assessed by the average path coefficient (APC), average $R$-square (ARS) (both should be significant at least at the 0.05 level), and the average variance inflation factor (AVIF) should be lower than 5 (Hair et al., 2011; Kock, 2011). These measures were within acceptable levels for the base model, as shown in Table 5.

\footnotetext{
"Insert Table 5 about here"
}

Further, to check the nature of relationships between complexity and novelty with arousal/pleasure (which are hypothesized as an inverted "U”), WarpPLS 3.0 software provides an output table indicating the types of relationships ("warped" or "linear"), between latent variables that are linked in the model. The results show four relationships as "warped".

For testing the mediation effect, we used the "indirect-effect" method (Kock, 2014), which allows multiple-mediation tests to be completed simultaneously and can be applied to linear and nonlinear paths and is available in Warp PLS 4.0. For a mediating effect to be considered significant, the indirect effect and the $p$-value must be significant at a specified level (<0.05). We also calculated Sobel's standard error (Kock, 2014) for each mediation link using an excel spreadsheet available on the WarpPLS website 
(http://www.scriptwarp.com/warppls/rscs/Kock_2013_MediationSobel.xls, accessed on 03 ${ }^{\text {rd }}$ July 2015) by inputting the various path coefficients and their standard errors generated by WarpPLS 4.0. The details are provided in Table 6.

"Insert Table 6 about here"

The affective responses (arousal and pleasure) mediate the relationship between legibility and preference, positively and significantly (indirect effect $=0.094, \mathrm{p}<0.001$ ). Sobel's test suggests that the indirect effect of legibility on preference through arousal $(\mathrm{t}$ $=3.773, \mathrm{p}<0.001)$ and pleasure $(\mathrm{t}=4.676, \mathrm{p}<0.001)$ is significant, suggesting $\mathrm{H} 1$ is supported. For mystery, the total indirect effect is positive and significant (indirect effect = $0.110, \mathrm{p}<0.001)$ and its indirect effect on preference through arousal $(\mathrm{t}=4.155, \mathrm{p}<0.001)$ and pleasure $(\mathrm{t}=5.391, \mathrm{p}<0.001)$ is also significant, supporting $\mathrm{H} 2$. In the case of coherence with preference, arousal and pleasure are found to be significant moderators (indirect effect $=0.110, \mathrm{p}<0.001$ ) and, as per Table 6 , its indirect effect on preference through arousal $(\mathrm{t}=4.890, \mathrm{p}<0.001)$ and pleasure $(\mathrm{t}=13.819, \mathrm{p}<0.001)$ is significant, supporting H3. Similarly, the results show significant mediation effects of arousal and pleasure in complexity - preference link (indirect effect $=0.106, p<0.001)$, indirect effect of complexity on preference through arousal $(\mathrm{t}=3.983, \mathrm{p}<0.001)$ and pleasure $(\mathrm{t}=5.242, \mathrm{p}<$ 0.001) is significant; and arousal and pleasure in novelty - preference link (indirect effect: $0.070, \mathrm{p}<0.001)$ indirect effect of novelty on preference through arousal $(\mathrm{t}=3.005, \mathrm{p}<$ 
$0.001)$ and pleasure $(\mathrm{t}=3.523, \mathrm{p}<0.001)$ is significant supporting hypotheses $\mathrm{H} 4$ and $\mathrm{H} 5$ respectively.

To test hypotheses $H \mathrm{Ha}$ through $H 5 \mathrm{a}$,- moderating role of the service contexts (i.e., utilitarian vs hedonic), we applied discrete moderation by employing multi-group analysis, as the hedonic and utilitarian service contexts were pre-fixed (Eberl, 2010; Hair et al., 2011; Kock, 2014). For both utilitarian and hedonic services contexts there were 700 observations each. The data set was divided into two groups (Group 1: utilitarian; Group 2: hedonic), and separate models were analyzed using WarpPLS 3.0. The path analysis of the two models is shown in Figures 4 and 5.

"Insert figures 4 \& 5 about here"

Just as for the base model, here also, the models are evaluated based on GoF, APC, ARS, and AVIF. Table 5 provides the Model fit indices (including GoF) for utilitarian and hedonic service contexts, and Table 6 provides $R^{2}$ values of all endogenous variables.

"Insert Tables $7 \& 8$ about here"

As can be inferred from figures $-03,04,05$ and table -08 the $\mathrm{R}^{2}$ value of arousal in base, utilitarian and hedonic models are $0.27,0.26$ and 0.33 respectively, which is moderate, 
yet significant (Falk and Miller, 1992; Hair et al., 2011). However, these values are lower than that of pleasure, possibly because of other factors which are not identified in this study. The path coefficients for each structural path were compared to interpret the effect between the groups. The structural differences were tested for significance with the pairwise $t$-test (Chin, 2000). Table 9 provides the comparison of the model path coefficients using the pairwise $t$-test. It is noted that the sign of $t$ depends on the direction of the difference between the sample means of two groups. If the mean of the utilitarian group is more than the mean of the hedonic group, it will produce a positive value of $t$, while if the mean of the utilitarian group is less than the mean of hedonic group it will produce a negative value of $t$.

"Insert Table 9 about here"

It is evident from Table 9 that, as hypothesized, the aesthetic dimension of legibility is found to have significant paths with the response variables of arousal and pleasure for utilitarian services, thereby supporting Hypothesis HIa. Mystery, complexity, and novelty are found to have significant path coefficients in the hedonic services context, thereby supporting Hypotheses $H 2 a, H 4 a$, and $H 5 a$. The paired comparison $t$-test (between hedonic and utilitarian service contexts) shows that the significance level for coherence versus arousal and pleasure are greater than 0.1 . This indicates that no significant differences exist between utilitarian and hedonic service contexts and thus, as hypothesized, $H 3 a$ is also supported. 


\section{Discussion and implications}

\section{Theoretical implications}

The present work extends the research on visual servicescape aesthetics by offering a holistic model for measuring consumers' perceptions of various aesthetic dimensions, their affective responses, and preferences. The research on visual aesthetics aspects in servicescapes is scarce in the extant literature (barring Orth and Wirtz, 2014, where the focus was on visual complexity), specifically from the viewpoint of the consumer. The recent review on servicescapes by Mari and Poggesi (2013) and the recent attempts by various researchers (e.g., Johnstone and Todd, 2012; Orth et al., 2012) emphasize the need for an enquiry in this area using a consumer perspective. This is in contrast to the existing studies in servicescapes, which have taken a manager/designer perspective by focusing mainly on the objective dimensions of color (e.g., Bellizzi and Hite, 1992), lighting (e.g., Quartier et al., 2008), layout (e.g., Flicker and Speer, 1990), cleanliness (e.g., Vilnai-Yavetz and Gilboa, 2010), etc.; and that, too, to a maximum of only four variables at a time (e.g., Babin et al., 2003; Spies et al., 1997).

Most studies in servicescapes applying collative and behavioral variables conceptualize and test linear relationships (e.g., Kumar and Karande, 2000; Orth and Wirtz, 2014). The literature indicates that a large number of relationships between variables describing natural and behavioral phenomena are seen to be non-linear (Kock, 2012). Conceptualizing and testing non-linear relationships provide a richer view of the associations between variables (Kock, 2012). In line with the other studies on landscapes (e.g., Berlyne, 1951; 1972; Nasar, 2002), this study also establishes the relationship between complexity and novelty with affective responses as curvilinear in the contexts of servicescapes as well. 
Finally, our findings suggest that consumers respond to the visual aesthetics of servicescapes differently depending on their perceptual service contexts. Many studies have attempted the moderating role of hedonic and utilitarian aspects in servicescapes like the impact of hedonic and utilitarian contexts on the relationship between affect and service quality (Jiang and Wang, 2006), scales for measuring hedonic and utilitarian shopping values (Babin et al.,1994), and scales for measuring hedonic and utilitarian motives (Arnold and Reynolds, 2003). This study adds one more facet as the findings may help scholars in understanding the role of service contexts in the relationship between the perceived visual servicescape aesthetics and consumers' affective responses, which has not been attempted earlier.

\section{Managerial implications}

Our findings should help managers employ more effective servicescape designs that support their efforts to attract and retain customers. Earlier studies have discussed that many managers did not give servicescape design a high priority in the company strategy (Walsh et $a l ., 1988)$. This study suggests that designing a servicescape with certain visual aesthetic qualities can create positive emotions and preferences in consumers. Therefore, the findings are expected to provide managers with the confidence to allocate resources for servicescape design, redesign, and furnishings, as they do for other marketing communication mixes. Service marketers, increasingly, find servicescape design of strategic relevance, consider consumers' views important and spend a significant amount of resources on servicescape designs. For instance, in re-designing its US stores, Starbucks asked designers to involve local communities in creating a look and feel reflecting local sentiments so that it could 
compete "with the charms of a local shop;"2 and projects this store environment as one of its key brand value propositions. ${ }^{3}$ Service marketers and their marketing research agencies may use the findings to develop servicescape pre-tests that test alternative designs at different stages of development (e.g., drawings, 3D models, interactive walk-throughs or mock-ups) before investing large sums in their execution.

The findings also suggest that the visual aesthetics of a servicescape depend greatly on the service context. The findings suggest that consumers will look for more legible and coherent visual appeals in a utilitarian service context (e.g., banks and hospitals). Therefore, the availability of signage, aisle, visual landmarks, lesser contrasting paints and textures, lesser headroom, more unified arrangements, and grouping of elements make it more preferable. In a hedonic context (e.g., spa and upscale restaurant) customers are influenced by moderate levels of complexity with coherence (or without clutter), high mystery, and moderate levels of novelty. Therefore, managers may include design aspects such as more contrasting colors and finishes, a variety of elements, a mix of light and dark spaces, visual screens, spacious rooms, and innovative design elements to make the servicescape more suitable for the context. Further, keeping in mind the dynamic nature of how consumers perceive a service context - hedonic or utilitarian - marketers would find this study useful in redesigning specific dimensions of servicescape in light of changing attitudes of consumers towards a service.

\footnotetext{
${ }^{2}$ B. Valleskey, "How Starbucks is Boosting Profits with Redesigned Stores", August 2, 2014, http://www.benzinga.com/news/14/08/4750880/how-starbucks-is-boosting-profits-with-redesigned-stores 3 "Store Design - Sustainable design and build methodologies are part of our DNA," May 25, 2016, http://www.starbucks.in/coffeehouse/store-design
} 


\section{Limitations and further research}

The first limitation is that although the study results generally support the proposed model, the results may be limited to the context of the study (i.e., banks, hospitals, upscale restaurant, and spa). Also, this study made use of discrete moderation by imposing categories a priori based on pre-testing on a separate set of respondents. Consumers may have varying levels of hedonic or utilitarian attitudes towards the same services. Furthermore, this study focuses only on the relationships between perceived visual servicescape aesthetics, affective responses, and preferences. It does not consider consumers' cognitive and physiological responses. The study also has the limitation of non-probability sampling. Since cultural, educational, and occupational aspects may not be fully represented, these factors may have influenced the results of the study. Future research may examine whether or not differences in findings across groups based on demographic and/or cultural factors exist. Another limitation is with regard to the age of the respondents as $85 \%$ of our respondents fall below the age of 34 years or millennials. Though we did check for the difference in responses between millennials verses non-millennials by testing two different models and comparing the fit indices, and did not find much difference, it would be interesting for future research to confirm whether millennials evaluate servicescape aesthetics differently when compared to older generations and explore how.

Future research investigating the effects of some potential moderating variables like consumer characteristics, including the overall visual aesthetics significance level that holds for a particular consumer (Bloch et al., 2003), visualizing/verbalizing tendencies of consumers (Holbrook, 1986) are likely to provide fruitful insights. Also, studies in actual or simulated servicescapes where the interplay of the dimensions can be easily perceived are 
likely to provide newer insights, future research may consider actual/ simulated environments to provide stimuli. Again, it is possible to extend the study by including other independent variables from environmental psychology such as familiarity (Baskaya et al., 2004) and visual scale (Clay and Smidt, 2004). Similarly, other dependent variables such as purchasing intentions and customer loyalty can also be examined. 
Table -1 : ANOVA Results : Low, Medium and High Group Scores

\begin{tabular}{|c|c|c|c|}
\hline & Arousal\# & Pleasure\# & Preference\# \\
\hline Legibility & $\begin{array}{l}M_{\text {high }}=4.939, M_{\text {medium }}= \\
4.356, M_{\text {low }}=3.745 \\
F(2,1397)=95.81^{*}\end{array}$ & $\begin{array}{l}M_{\text {high }}=5.468, M_{\text {medium }}= \\
4.642, M_{\text {low }}=3.854 \\
F(2,1397)=159.69^{*}\end{array}$ & $\begin{array}{l}M_{\text {high }}=5.168, M_{\text {medium }}= \\
4.202, M_{\text {low }}=3.379 \\
F(2,1397)=144.03 *\end{array}$ \\
\hline Mystery & $\begin{array}{l}M_{\text {high }}=4.865, M_{\text {medium }}= \\
4.236, M_{\text {low }}=3.683 \\
F(2,1397)=81.42^{*}\end{array}$ & $\begin{array}{l}M_{\text {high }}=5.349, M_{\text {medium }}= \\
4.525, M_{\text {low }}=3.585 \\
F(2,1397)=136.96^{*}\end{array}$ & $\begin{array}{l}M_{\text {high }}=5.053, M_{\text {medium }}= \\
4.032, M_{\text {low }}=3.187 \\
F(2,1397)=130.10 *\end{array}$ \\
\hline Coherence & $\begin{array}{l}M_{\text {high }}=4.846, M_{\text {medium }}= \\
4.387, M_{\text {low }}=3.551 \\
F(2,1397)=105.45^{*}\end{array}$ & $\begin{array}{l}M_{\text {high }}=5.435, M_{\text {medium }}= \\
4.387, M_{\text {low }}=3.381 \\
F(2,1397)=2911.15^{*}\end{array}$ & $\begin{array}{l}M_{\text {high }}=5.162, M_{\text {medium }}= \\
3.810, M_{\text {low }}=2.963 \\
F(2,1397)=280.03 *\end{array}$ \\
\hline Complexity & $\begin{array}{l}M_{\text {high }}=4.902, M_{\text {medium }}= \\
4.372, M_{\text {low }}=3.536 \\
F(2,1397)=87.38^{*}\end{array}$ & $\begin{array}{l}M_{\text {high }}=5.381, M_{\text {medium }}= \\
4.698, M_{\text {low }}=3.575 \\
F(2,1397)=129.23^{*}\end{array}$ & $\begin{array}{l}M_{\text {high }}=5.087, M_{\text {medium }}= \\
4.262, M_{\text {low }}=3.021 \\
F(2,1397)=125.45^{*}\end{array}$ \\
\hline Novelty & $\begin{array}{l}M_{\text {high }}=4.885, M_{\text {medium }}= \\
4.378, M_{\text {low }}=3.852 \\
F(2,1397)=64.63^{*}\end{array}$ & $\begin{array}{l}M_{\text {high }}=5.306, M_{\text {medium }}= \\
4.750, M_{\text {low }}=3.581 \\
F(2,1397)=82.16^{*}\end{array}$ & $\begin{array}{l}M_{\text {high }}=4.987, M_{\text {medium }}= \\
4.343, M_{\text {low }}=2.934 \\
F(2,1397)=82.30^{*}\end{array}$ \\
\hline
\end{tabular}

$*=p<0.001 ;$ \# dependent variables.

Table -2 : ANOVA Results - Differential Responses by Different Images

Hedonic Services $(\mathrm{n}=700)$

\begin{tabular}{l|c|l|l|l|l|l|l|c}
\hline & COM & COH & LEG & MYS & NOV & PLS & ARO & PREF \\
\hline $\begin{array}{l}\boldsymbol{F}(\mathbf{2 9 , 6 7 0 )} \\
\text { Values }\end{array}$ & $18.23^{*}$ & $12.05^{*}$ & $11.46^{*}$ & $12.11^{*}$ & $12.11^{*}$ & $21.53^{*}$ & $7.79 *$ & $13.69 *$ \\
\hline Subsets** & 7 & 11 & 8 & 8 & 8 & 4 & 8 & 8 \\
\hline
\end{tabular}




\begin{tabular}{l}
\hline Utilitarian Services $(\mathrm{n}=700)$ \\
\begin{tabular}{l|c|c|c|c|c|c|c|c}
$\boldsymbol{F}(\mathbf{2 9 , 6 7 0})$ & $22.6^{*}$ & $14.19^{*}$ & $11.63^{*}$ & $12.12^{*}$ & $16.96^{*}$ & $17.34^{*}$ & $8.72^{*}$ & $14.54^{*}$ \\
Values & & & & & & & & \\
\hline Subsets** & 10 & 8 & 10 & 11 & 10 & 6 & 8 & 9 \\
\hline
\end{tabular}
\end{tabular}

$*=p<0.001 ; * *$ Numbers of Homogeneous Subsets using REGWQ method

LEG = legibility; MYS = mystery; $\mathrm{COH}=$ coherence COM = complexity NOV = novelty; $\mathrm{ARO}=$ arousal; $\mathrm{PLS}=$ pleasure; $\mathrm{PREF}=$ preference .

Table 3. Latent variable coefficients - base model

\begin{tabular}{l|c|c|c|c|c|c|c|c}
\hline & $\begin{array}{c}\text { Arous } \\
\mathbf{a l}^{*}\end{array}$ & $\begin{array}{c}\text { Pleasu } \\
\text { re }^{*}\end{array}$ & $\begin{array}{c}\text { Prefer } \\
\text { ence* }\end{array}$ & $\begin{array}{c}\text { Legibili } \\
\text { ty }^{* *}\end{array}$ & $\begin{array}{c}\text { Myste } \\
\text { ry }^{* *}\end{array}$ & $\begin{array}{c}\text { Cohere } \\
\text { nce** }^{* *}\end{array}$ & $\begin{array}{c}\text { Comple } \\
\text { xity }^{* *}\end{array}$ & $\begin{array}{c}\text { Novelty } \\
* *\end{array}$ \\
\hline $\begin{array}{l}\text { Composite } \\
\text { reliability }\end{array}$ & 0.904 & 0.952 & 0.939 & na & na & na & na & na \\
\hline $\begin{array}{l}\text { Cronbach's } \\
\text { alpha }\end{array}$ & 0.866 & 0.941 & 0.913 & na & na & na & na & na \\
\hline $\begin{array}{l}\text { Average } \\
\text { variance } \\
\text { extracted } \\
\text { (AVE) }\end{array}$ & 0.655 & 0.739 & 0.794 & 0.641 & 0.520 & 0.736 & 0.663 & 0.465 \\
\hline $\begin{array}{l}\text { Full } \\
\text { collinearity } \\
\text { VIFs }\end{array}$ & 2.147 & 3.290 & 2.648 & 1.679 & 1.670 & 1.980 & 1.595 & 1.432 \\
\hline
\end{tabular}

Notes: ${ }^{*}=$ Reflective variables; ${ }^{* *}=$ formative variables; na $=$ not applicable 
Table 4. Correlations and square root of AVE - base model

\begin{tabular}{|c|c|c|c|c|c|c|c|c|}
\hline & $\begin{array}{l}\text { Legibili } \\
\text { ty }\end{array}$ & Mystery & $\begin{array}{l}\text { Cohere } \\
\text { nce }\end{array}$ & $\begin{array}{l}\text { Comple } \\
\text { xity }\end{array}$ & Novelty & Arousal & $\begin{array}{l}\text { Pleasur } \\
\text { e }\end{array}$ & $\begin{array}{l}\text { Preferen } \\
\text { ce }\end{array}$ \\
\hline $\begin{array}{l}\text { Legibilit } \\
\mathbf{y}\end{array}$ & $(0.801)$ & & & & & & & \\
\hline Mystery & 0.482 & $(0.721)$ & & & & & & \\
\hline $\begin{array}{l}\text { Coheren } \\
\text { ce }\end{array}$ & 0.515 & 0.469 & $(0.858)$ & & & & & \\
\hline $\begin{array}{l}\text { Complex } \\
\text { ity }\end{array}$ & 0.428 & 0.409 & 0.280 & $(0.814)$ & & & & \\
\hline Novelty & -0.314 & -0.364 & -0.208 & -0.51 & $(0.631)$ & & & \\
\hline Arousal & 0.396 & 0.395 & 0.414 & 0.339 & -0.304 & $(0.809)$ & & \\
\hline Pleasure & 0.491 & 0.481 & 0.607 & 0.39 & -0.308 & 0.714 & (0.859) & \\
\hline $\begin{array}{l}\text { Preferen } \\
\text { ce }\end{array}$ & 0.488 & 0.469 & 0.619 & 0.39 & -0.314 & 0.607 & 0.743 & $(0.891)$ \\
\hline
\end{tabular}

Notes: Diagonal elements - Square root of AVE - between constructs and their measures; off-diagonal elements - correlations between constructs.

Table 5. Model fit indices - base model

\begin{tabular}{l|l|l|l}
\hline GoF & APC & ARS & AVIF \\
\hline $\mathbf{0 . 3 4 8}$ & $0.199^{*}$ & $0.435^{*}$ & 1.616 \\
\hline
\end{tabular}

Note: $*=p<0.001$.

Table 6. Base model Mediation Analysis Results

\begin{tabular}{c|l|l|c}
\hline \multicolumn{1}{c|}{ Links } & \multicolumn{1}{c|}{ Sobel's SE } & t-value & $\boldsymbol{p}$-Value \\
\hline LEG $\rightarrow$ ARO $\rightarrow$ PREF & 0.0049 & 3.773 & $<0.001$ \\
\hline
\end{tabular}




\begin{tabular}{l|l|l|l}
\hline LEG $\rightarrow$ PLS $\rightarrow$ PREF & 0.0163 & 4.676 & $<0.001$ \\
\hline $\mathrm{MYS} \rightarrow$ ARO $\rightarrow$ PREF & 0.0053 & 4.155 & $<0.001$ \\
\hline $\mathrm{MYS} \rightarrow$ PLS $\rightarrow$ PREF & 0.0164 & 5.391 & $<0.001$ \\
\hline $\mathrm{COH} \rightarrow$ ARO $\rightarrow$ PREF & 0.0066 & 4.890 & $<0.001$ \\
\hline $\mathrm{COH} \rightarrow$ PLS $\rightarrow$ PREF & 0.0190 & 13.819 & $<0.001$ \\
\hline $\mathrm{COM} \rightarrow$ ARO $\rightarrow$ PREF & 0.0051 & 3.983 & $<0.001$ \\
\hline $\mathrm{COM} \rightarrow$ PLS $\rightarrow$ PREF & 0.0163 & 5.242 & $<0.001$ \\
\hline NOV $\rightarrow$ ARO $\rightarrow$ PREF & 0.0044 & 3.005 & $<0.001$ \\
\hline NOV $\rightarrow$ PLS $\rightarrow$ PREF & 0.0161 & 3.523 & $<0.001$ \\
\hline
\end{tabular}

Notes: LEG = legibility; MYS = mystery; $\mathrm{COH}=$ coherence $; \mathrm{COM}=$ complexity; $\mathrm{NOV}=$ novelty $; \mathrm{ARO}=$ arousal; $\mathrm{PLS}=$ pleasure; $\mathrm{PREF}=$ preference

Table 7. Model fit indices - utilitarian and hedonic services contexts

Utilitarian services context

\begin{tabular}{l|l|l|l}
\hline GoF & APC & ARS & AVIF \\
\hline $\mathbf{0 . 3 2 7}$ & $0.198^{*}$ & $0.417^{*}$ & 1.445 \\
& & & \\
\hline
\end{tabular}

Hedonic Services Context

\begin{tabular}{l|l|l|l}
\hline GoF & APC & ARS & AVIF \\
\hline $\mathbf{0 . 4 0 1}$ & $0.210^{*}$ & $0.491^{*}$ & 1.759 \\
\hline$*=p<0.001$. & & & \\
\hline \multicolumn{3}{|l}{}
\end{tabular}


Table 8. $R^{2}$ for the models - utilitarian and hedonic services contexts

\begin{tabular}{l|l|l}
\hline Dependent construct & $\boldsymbol{R}^{\mathbf{2}}$ (utilitarian) & $\boldsymbol{R}^{\mathbf{2}}$ (hedonic) \\
\hline Arousal & 0.26 & 0.33 \\
\hline Pleasure & & \\
\hline
\end{tabular}

Table 9: Moderation - path coefficients comparisons - utilitarian and hedonic service contexts

\begin{tabular}{l|l|l|l|l|l|l}
\hline \multicolumn{1}{c|}{$\begin{array}{c}\text { Moderation - path } \\
\text { coefficients comparisons }\end{array}$} & \multicolumn{2}{|c|}{$\begin{array}{c}\text { Group 1 } \\
\text { Utilitarian }\end{array}$} & \multicolumn{2}{c}{ Group 2 Hedonic } & \multicolumn{2}{c}{ Pair $t$-test } \\
\hline Paths & $\boldsymbol{\beta}$ & $p$-value & $\boldsymbol{\beta}$ & $p$-value & $\begin{array}{l}\boldsymbol{t} \text { - } \\
\text { Value }\end{array}$ & $p$-Value \\
\hline Legibility $\rightarrow$ Arousal & $\mathbf{0 . 1 8 8}$ & $<0.001$ & 0.049 & 0.112 & 2.420 & 0.008 \\
\hline Legibility $\rightarrow$ Pleasure & $\mathbf{0 . 1 8 9}$ & $<0.001$ & 0.055 & 0.077 & 2.420 & 0.008 \\
\hline Mystery $\rightarrow$ Arousal & 0.054 & 0.102 & $\mathbf{0 . 2 0 3}$ & $<0.001$ & 2.395 & 0.008 \\
\hline Mystery $\rightarrow$ Pleasure & 0.072 & 0.031 & $\mathbf{0 . 1 9 9}$ & $<0.001$ & -2.304 & 0.010 \\
\hline Coherence $\rightarrow$ Arousal & $\mathbf{0 . 2 4 2}$ & $<0.001$ & $\mathbf{0 . 1 8 4}$ & $<0.001$ & 0.976 & 0.164 \\
\hline Coherence $\rightarrow$ Pleasure & $\mathbf{0 . 4 3 3}$ & $<0.001$ & $\mathbf{0 . 3 7 4}$ & $<0.001$ & 1.176 & 0.119 \\
\hline Complexity $\rightarrow$ Arousal & 0.174 & 0.149 & $\mathbf{0 . 1 4 8}$ & $<0.001$ & 0.291 & 0.385 \\
\hline Complexity $\rightarrow$ Pleasure & $\mathbf{0 . 1 8 2}$ & 0.003 & $\mathbf{0 . 1 3 2}$ & $<0.001$ & 0.505 & 0.307 \\
\hline Novelty $\rightarrow$ Arousal & 0.034 & 0.230 & $\mathbf{0 . 1 6 9}$ & $<0.001$ & -1.968 & 0.025 \\
\hline & & & & & & \\
\hline
\end{tabular}




\begin{tabular}{l|l|l|l|l|l|l}
\hline Novelty $\rightarrow$ Pleasure & 0.052 & 0.092 & $\mathbf{0 . 1 7 9}$ & $<0.001$ & -1.527 & 0.064 \\
\hline
\end{tabular}

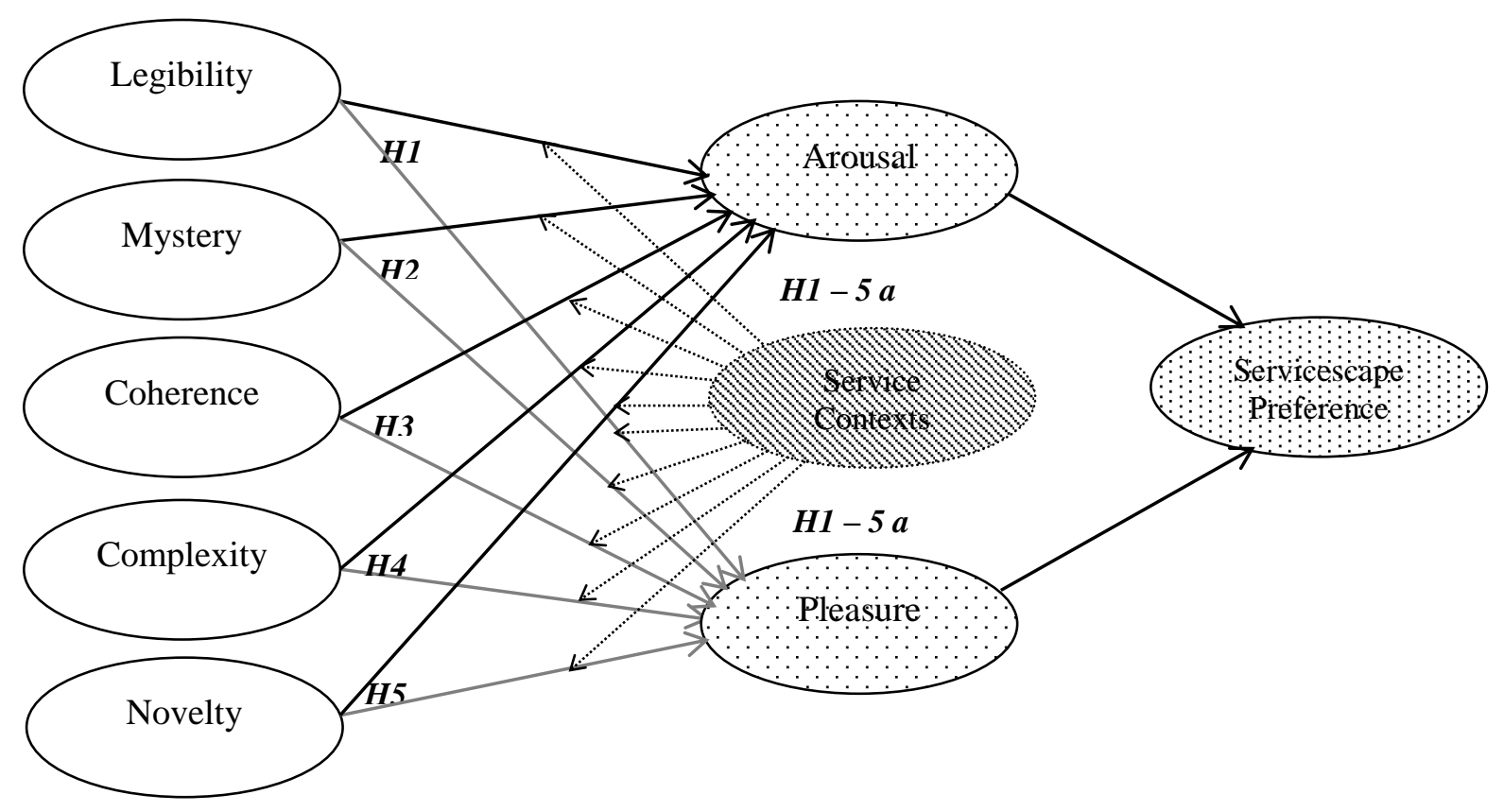

Fig.1 The proposed model

Fig. 2 : X-Y plot on Classification of Service Contexts

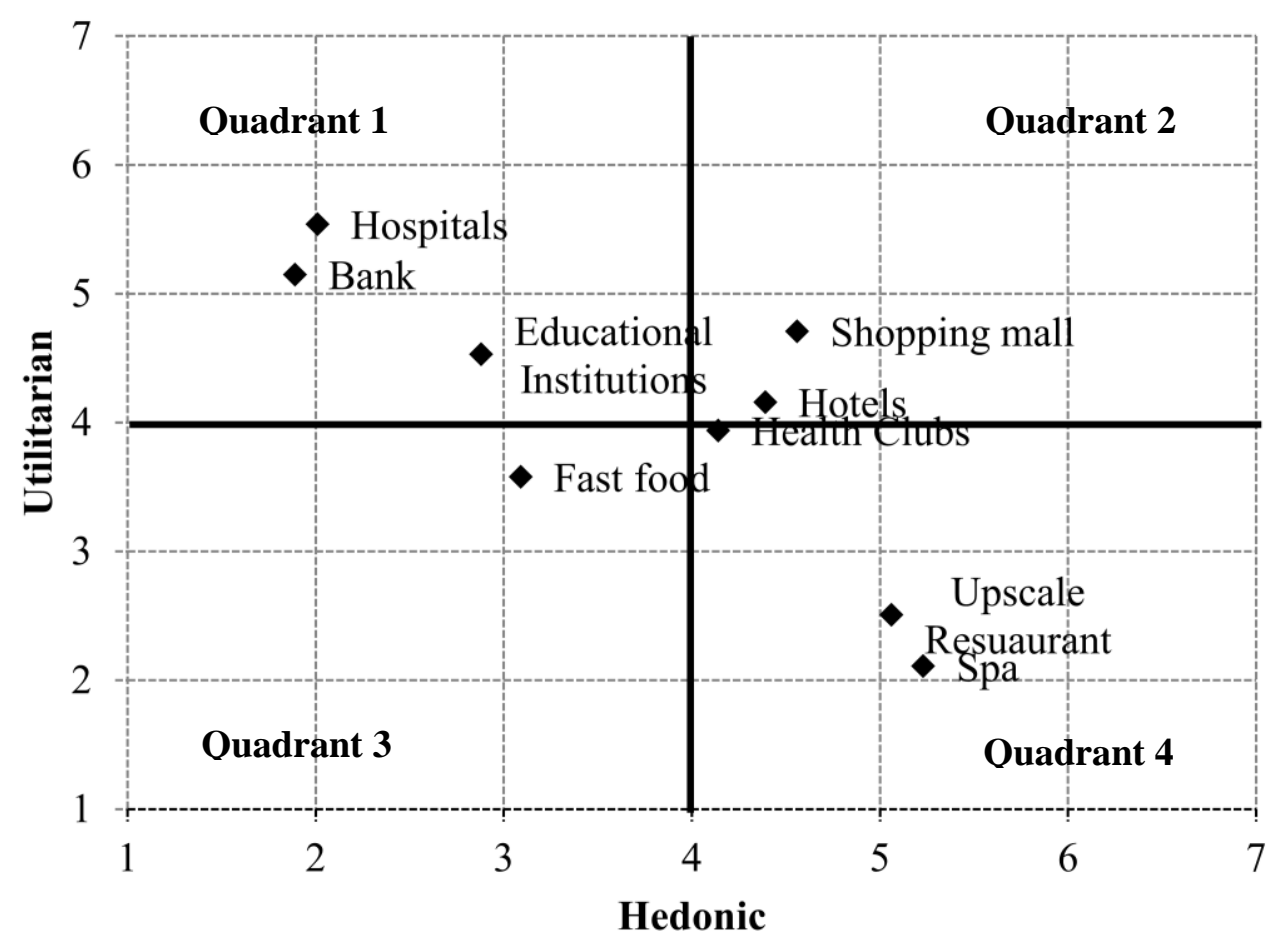




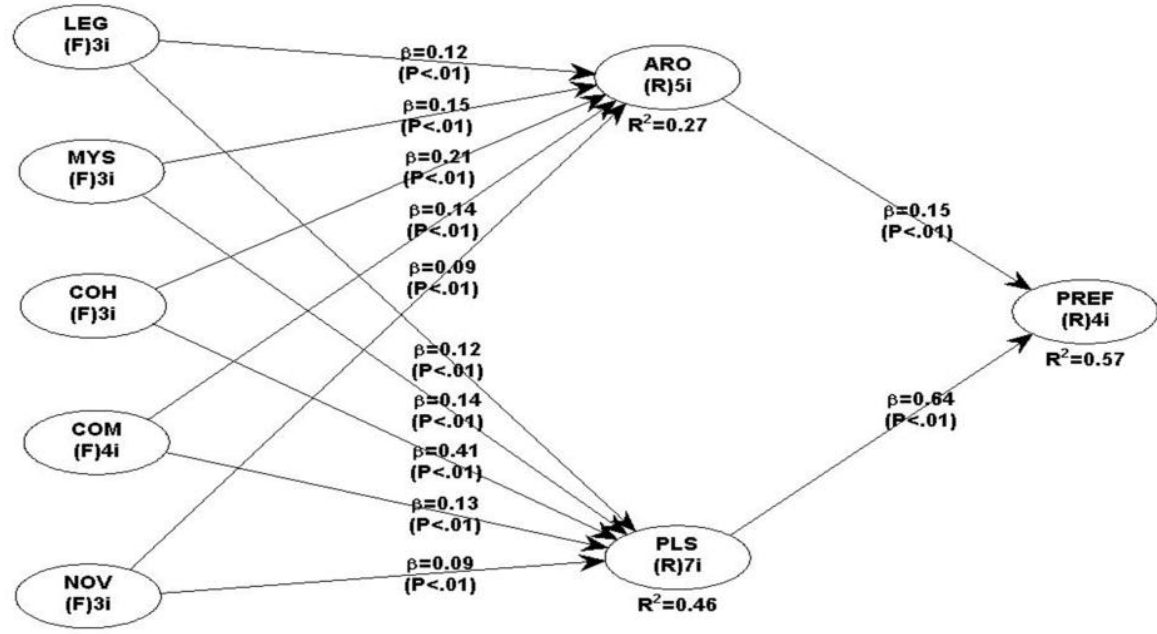

Fig.3 Path analysis - Base Model

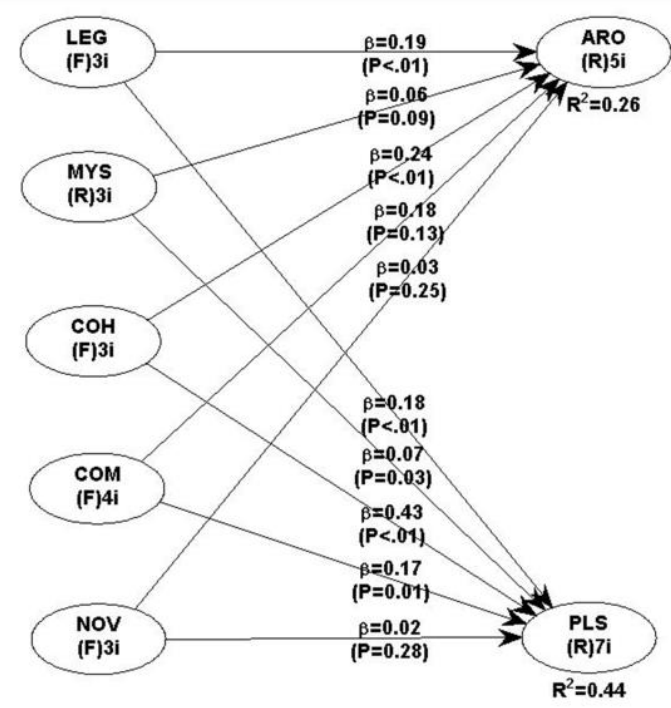

Fig.4: Path Analysis of the Utilitarian Services Model

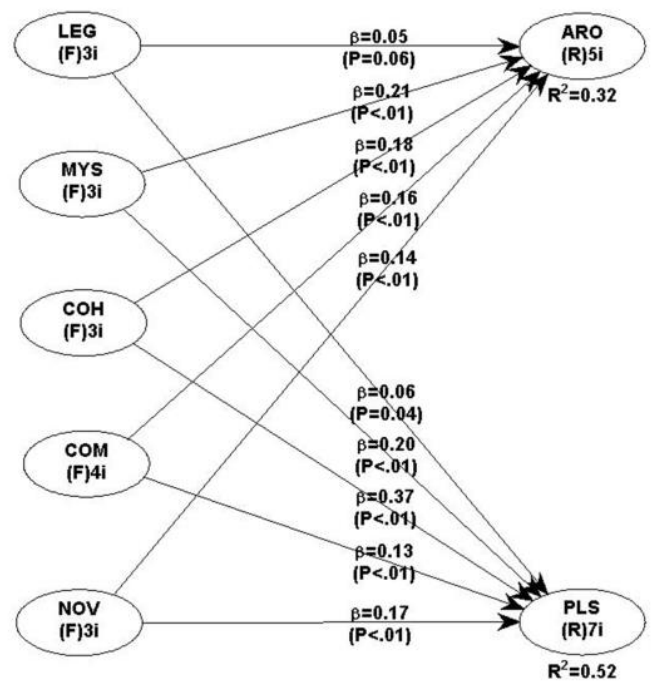

Fig.5: Path Analysis of the Hedonic Services Model 


\section{References:}

Abubakar, B. (2010), "Developing a framework for understanding a tourism service setting: an exploratory study", Services Marketing Quarterly, Vol. 23 No. 3, pp. 17-34.

Addis, M. and Holbrook, M.B. (2001), “On the conceptual link between mass customisation and experiential consumption: an explosion of subjectivity", Journal of Consumer Behaviour, Vol. 1 No. 1, pp. 50-66.

Akbar, M., Kamal, M.S., Maulan, S. and Davoodi, S.R. (2011), "Determining the visual preference of urban landscapes", Scientific Research and Essays, Vol. 6 No. 9, pp. 1991-97. Arnold, M.J., and Reynolds, K.E. (2003). "Hedonic shopping motivations", Journal of Retailing, Vol. 79, No. 2, pp. 77-95.

Babin, B.J., Darden, W.R. and Griffin, M. (1994), "Work and/or fun: measuring hedonic and utilitarian shopping value", Journal of Consumer Research, pp. 644-56.

Babin, B.J., Hardesty, D.M. and Suter, T.A. (2003), "Color and shopping intentions: the intervening effect of price fairness and perceived affect", Journal of Business Research, Vol. 56 No. 7 , pp. 541-51.

Baker, J. (1986), "The role of the environment in marketing services: the consumer perspective", The Services Challenge: Integrating for Competitive Advantage, Vol. 1 No.1, pp. 79-84.

Baker, J., Parasuraman, A., Grewal, D. and Voss, G.B. (2002), "The influence of multiple store environment cues on perceived merchandise value and patronage intentions", Journal of Marketing, Vol. 66 No. 2, pp. 120-41. 
Ballantine, P.W., Jack, R. and Parsons, A.G. (2010), "Atmospheric cues and their effect on the hedonic retail experience", International Journal of Retail \& Distribution Management, Vol. 38 No. 8, pp. 641-53.

Baskaya, A., Wilson, C. and Özcan, Y.Z. (2004), "Wayfinding in an unfamiliar environment different spatial settings of two polyclinics", Environment and Behavior, Vol. 36 No. 6, pp. 839-67.

Batra, R. and Ahtola, O.T. (1991), "Measuring the hedonic and utilitarian sources of consumer attitudes", Marketing Letters, Vol. 2, No. 2, pp. 159-70.

Bellizzi, J.A. and Hite, R.E. (1992), "Environmental color, consumer feelings, and purchase likelihood", Psychology \& Marketing, Vol. 9 No. 5, pp. 347-63.

Berlyne, D.E. (1951), “Attention, perception and behavior theory”, Psychological Review, Vol. 58 No. 2, pp. 137-46.

Berlyne, D.E. (1972), "Ends and means of experimental aesthetics", Canadian Journal of Psychology/Revue Canadienne de Psychologie, Vol. 26 No. 4, pp. 303-25.

Bitner, M.J. (1990), "Evaluating service encounters: the effects of physical surroundings and employee responses", The Journal of Marketing, Vol. 54 No. 2, pp. 69-82.

Bitner, M.J. (1992), “Servicescapes: the impact of physical surroundings on consumers and employees", The Journal of Marketing, Vol. 56 No. 2, pp. 57-71.

Bloch, P.H., Brunel, F.F. and Arnold, T.J. (2003), "Individual differences in the centrality of visual product aesthetics: concept and measurement", Journal of Consumer Research, Vol. 29 No. 4, pp. 551-65.

Blythe, J. (1999), "Innovativeness and newness in high-tech consumer durables", Journal of Product \& Brand Management, Vol. 8 No. 5, pp. 415-29. 
Bonfanti, A. (2013)," Towards an approach to signage management quality (SMQ)", Journal of Services Marketing, Vol. 27 No.4, pp. 312-321.

Booms, B.H. and Bitner, M.J. (1982), "Marketing services by managing the environment", Cornell Hotel and Restaurant Administration Quarterly, Vol. 23 No. 1, pp. 35-40.

Cheng, C.-K. (2007), "Understanding visual preferences for landscapes: an examination of the relationship between aesthetics and emotional bonding", doctoral dissertation, Texas A\&M University.

Chin, W.W. (2000), "Frequently asked questions - Partial least squares \& PLS-Graph", available at: http://disc-nt.cba.uh.edu/chin/plsfaq.htm (accessed 20 December 2012).

Clay, G.R. and Smidt, R.K. (2004), "Assessing the validity and reliability of descriptor variables used in scenic highway analysis." Landscape and Urban Planning, Vol. 66 No. 4, pp. 239-255.

Cox, D. and Cox, A. (1994), "The effect of arousal seeking tendency on consumer preferences for complex product designs", Advances in Consumer Research, Vol. 21, pp. $554-54$.

Cox, D. and Cox, A.D. (2002), "Beyond first impressions: The effects of repeated exposure on consumer liking of visually complex and simple product designs." Journal of the Academy of Marketing Science, Vol. 30 No. 2, pp. 119-30.

Crilly, N., Moultrie, J. and Clarkson, P. J. (2004), "Seeing things: consumer response to the visual domain in product design”, Design Studies, Vol. 25 No. 6, pp. 547-77.

Daniel, T.C. and Boster, R.S. (1976), "Measuring landscape esthetics: the scenic beauty estimation method", In Rocky Mountain Forest and Range Experiment Station, Fort Collins, Co. 
Diamantopoulos, A. and Winklhofer, H.M. (2001), "Index construction with formative indicators: an alternative to scale development", Journal of Marketing Research, Vol. 38 No. 2, pp. 269-77.

Dogu, U. and Erkip, F. (2000), "Spatial factors affecting wayfinding and orientation: a case study in a shopping mall”, Environment and Behavior, Vol. 32 No. 6, pp. 731-55.

Donovan, R.J. and Rossiter, J.R. (1982), "Store atmosphere: an environmental psychology approach”, Journal of Retailing, Vol. 58 No. 1, pp. 34-57.

Donovan, R.J., Rossiter, J.R., Marcoolyn, G. and Nesdale, A. (1994), "Store atmosphere and purchasing behavior", Journal of Retailing, Vol. 70 No.3, pp. 283-94.

Eberl, M. (2010), "An application of PLS in multi-group analysis: the need for differentiated corporate-level marketing in the mobile communications industry", in Handbook of Partial Least Squares, Springer Berlin Heidelberg, London, pp. 487-514.

Eckman, M. and Wagner, J. (1994), “Judging the attractiveness of product design: the effect of visual attributes and consumer characteristics", Advances in Consumer Research, Vol. 21, pp. $558-60$.

Falk, R.F., and Miller, N.B. (1992), A Primer for Soft Modeling, University of Akron Press, Akron, $\mathrm{OH}$.

Farr, A. C., Kleinschmidt, T., Yarlagadda, P., and Mengersen, K. (2012), “Wayfinding: A simple concept, a complex process”, Transport Reviews, Vol.32 No. 6, pp. 715-743.

Finlay, K., Kanetkar, V., Londerville, J. and Marmurek, H.H.C (2006), “The physical and psychological measurement of gambling environments", Environment and Behavior, Vol. 38 No. 4 , pp. 570-81. 
Flicker, M.H., and Speer, W.C. (1990), "Emotional responses to store layout and design: An experimental approach", in Parasuraman, A. et al. (Eds.) AMA educators' proceedings: enhancing knowledge development in marketing, American Marketing Association, Chicago, IL, pp. 1-5.

Foxall, G.R. and Yani-de-Soriano, M.M. (2005), "Situational influences on consumers' attitudes and behavior", Journal of Business Research, Vol. 58 No. 4, pp. 518-25. Gefen, D.; Pavlou, P.A.; Benbasat, I.; McKnight, D.H.; Stewart, K.; and Straub, D.W. (2006) "Should institutional trust matter in information systems research?" Communications of the AIS, Vol.19,(7), pp. 205-222.

Gifford, R., Hine, D.W., Muller-Clemm, W., Reynolds, A.J. and Shaw, K.T. (2000), "Decoding modern architecture - a lens model approach for understanding the aesthetic differences of architects and laypersons", Environment and Behavior, Vol. 32, pp. 163-87. Gilboa, S. and Rafaeli, A. (2003), "Store environment, emotions and approach behaviour: applying environmental aesthetics to retailing", The International Review of Retail, Distribution and Consumer Research, Vol. 13 No. 2, pp. 195-211.

Godey, B., Lagier, J. and Pederzoli, D. (2009), "A measurement scale of "aesthetic style" applied to luxury goods stores", International Journal of Retail \& Distribution Management, Vol. 37 No. 6, pp. 527-37.

Grayson, R.A. and McNeill, L.S. (2009), "Using atmospheric elements in service retailing: understanding the bar environment", Journal of Services Marketing, Vol. 23 No. 7, pp. 51727.

Griffiths, M.A. and Gilly, M.C. (2012), "Dibs! Consumer territorial behaviors." Journal of Service Research, Vol. 15 No. 2, pp. 131-149. 
Hagerhall, C.M. (2001), "Consensus in landscape preference judgements", Journal of Environmental Psychology, Vol. 21 No. 1, pp. 83-92.

Hair, J.F., Ringle, C.M. and Sarstedt, M. (2011), "PLS-SEM: Indeed a silver bullet", The Journal of Marketing Theory and Practice, Vol. 19 No. 2, pp. 139-52.

Hanyu, K. (2000), "Visual properties and affective appraisals in residential areas in daylight", Journal of Environmental Psychology, Vol. 20 No. 3, pp. 273-84.

Hekkert, P., Snelders, D., and van Wieringen, P.C.W. (2003), "Most advanced, yet acceptable: typicality and novelty as joint predictors of aesthetic preference in industrial design”, British Journal of Psychology, Vol. 94, pp. 111-124.

Herzog, T.R. (2004), “Legibility, mystery, and visual access as predictors of preference and perceived danger in forest settings without pathways", Environment and Behavior, Vol. 36, pp. $659-77$.

Herzog, T.R. and Bryce, A.G. (2007), "Mystery and preference in within-forest settings", Environment and Behavior, Vol. 39 No. 6, pp. 779-96.

Herzog, T.R., Kaplan, S., and Kaplan, R. (1982), The prediction of preference for unfamiliar urban places, Population and Environment, Vol. 5 No. 1, pp. 43-59.

Herzog, T.R. and Kropscott, L.S. (2004), "Legibility, mystery, and visual access as predictors of preference and perceived danger in forest settings without pathways", Environment and Behaviour, Vol. 36 No. 5, 659-77.

Herzog, T.R. and Kutzli, G.E. (2002), "Preference and perceived danger in field/forest settings“, Environment and Behavior, Vol. 34 No. 6, pp. 819-35.

Herzog, T.R. and Leverich, O.L. (2003), "Searching for legibility", Environment and Behaviour, Vol. 35 No. 4, pp. 459-77. 
Herzog, T.R. and Stark, J.L. (2004), “Typicality and preference for positively and negatively valued environmental settings", Journal of Environmental Psychology, Vol. 24 No. 1, pp. 8592.

Herzog, T.R., Maguire, P. and Nebel, M.B. (2003),"Assessing the restorative components of environments", Journal of Environmental Psychology, Vol. 23 No. 2, pp. 159-70.

Hightower Jr, R., Brady, M.K. and Baker, T.L. (2002), "Investigating the role of the physical environment in hedonic service consumption: an exploratory study of sporting events", Journal of Business Research, Vol. 55 No. 9, pp. 697-707.

Hirschman, E.C. (1983), "Aesthetics, ideologies and the limits of the marketing concept", The Journal of Marketing, Vol. 47 No. 3, pp. 45-56.

Hirschman, E.C., Holbrook, M.B. (1982), "Hedonic consumption: emerging concepts, methods and propositions“, Journal of Marketing, Vol. 46 No. 3, pp. 92-101.

Holbrook, M.B. (1986), “Aims, concepts, and methods for the representation of individual differences in esthetic responses to design features", Journal of Consumer Research, Vol. 13 No. 3, pp. 337-47.

Ikemi, M. (2005), "The effects of mystery on preference for residential facades", Journal of Environmental Psychology, Vol. 25 No. 2, pp. 167-73.

Jarvis C. B. Mackenzie S. B and Podsakoff P. M (2003), “A critical review of construct indicator s and measurement model misspecification in marketing and consumer research". Journal of Consumer Research Vol. 30 No.3; pp. 199-218.

Jiang, Y. and Wang, C.L. (2006), "The impact of affect on service quality and satisfaction: the moderation of service contexts", Journal of Services Marketing, Vol. 20 No. 4, pp. 21118. 
Johnstone, M.-L. and Todd, S. (2012), "Servicescapes: the role that place plays in stay-athome mothers' lives", Journal of Consumer Behaviour, Vol. 11 No. 6, pp. 443-53.

Joseph-Mathews, S., Bonn, M.A. and Snepenger, D. (2009), "Atmospherics and consumers' symbolic interpretations of hedonic services", International Journal of Culture, Tourism and Hospitality Research, Vol. 3 No. 3, pp. 193-210.

Kaplan, S. (1979), "Perception and landscape: conceptions and misconceptions", in National conference on applied techniques for analysis and management of the visual resource, pp. $23-25$.

Kaplan, S. (1987), "Aesthetics, affect, and cognition environmental preference from an evolutionary perspective", Environment and Behaviour, Vol. 19 No. 1, pp. 3-32. Kaplan, S. and Kaplan, R. (1989), "Environmental preference - A comparison of four domains of predictors", Environment and Behaviour, Vol. 21 No. 5, pp. 509-30. Kempf, D.S. (1999), "Attitude formation from product trial: distinct roles of cognition and affect for hedonic and functional products", Psychology \& Marketing, Vol. 16 No. 1, pp. 3550.

Kock, N. (2011), "Using WarpPLS in e-collaboration studies: mediating effects, control and second order variables, and algorithm choices", International Journal of e-Collaboration (IJeC), Vol. 7 No. 3, pp. 1-13.

Kock, N. (2012), "WarpPLS 3.0", User Manual, ScriptWarp Systems, Laredo, Texas.

Kock, N. (2014), “Advanced mediating effects tests, multi-group analyses, and measurement model assessments in PLS-based SEM", International Journal of e-Collaboration, Vol.10 No.1, 1-13. 
Kotler, P. (1973), "Atmospherics as a marketing tool", Journal of Retailing, Vol. 49 No. 4, pp. 48-64.

Kumar, D.S., Purani, K. and Sahadev, S. (2013), "Conceptualising visual servicescape aesthetics: an application of environmental psychology", The Marketing Review, Vol. 13 No. 4, pp. 347-76.

Kumar, V. and Karande, K. (2000). "The effect of retail store environment on retailer performance", Journal of Business Research, Vol. 49 No. 2, pp. 167-81.

Larson, R. and Delespaul, P.A.E.G. (1992), "Analyzing experience sampling data: a guidebook for the perplexed", in deVries, M. W. (Ed.), The Experience of Psychopathology: Investigating Mental Disorders in their Natural Settings, Cambridge University Press, New York, NY, pp. 58-78.

Leder, H. and Carbon, C.-C. (2005), "Dimensions in appreciation of car interior design", Applied Cognitive Psychology, Vol. 19 No. 5, pp. 603-18.

Lynch, K. (1960), The Image of the City, MIT Press, Cambridge, MA.

Malhotra, N.K. (2007), Marketing Research: An Applied Orientation, 5th edition, Pearson Education India.

Mari, M., and Poggesi, S (2013), "Servicescape cues and consumer behavior: a systematic literature review and research agenda", The Service Industries Journal, Vol. 33 No. 2, pp. $171-99$.

Martindale, C. and Moore, K. (1988), "Priming, prototypicality , and preference", Journal of Experimental Psychology: Human Perception and Performance, Vol. 14 No. 4, pp. 661-70. Martindale, C., Moore, K. and Borkum, J. (1990), “Aesthetic preference: anomalous findings for Berlyne's psychobiological theory", The American Journal of Psychology, pp. 53-80. 
Mehrabian, A. and Russell, J.A. (1974), An Approach to Environmental Psychology, The MIT Press, Cambridge, MA.

McKnight, D. H., \& Chervany, N. L. (2001, January). Conceptualizing trust: A typology and e-commerce customer relationships model. In System Sciences, 2001. Proceedings of the 34th Annual Hawaii International Conference on (pp. 10-pp). IEEE.

Michon, R., Chebat, J.-C. and Turley, L.W. (2005), "Mall atmospherics: the interaction effects of the mall environment on shopping behavior", Journal of Business Research, Vol. 58 No. 5 , pp. 576-83.

Nasar, J.L. (1984), "Visual preferences in urban street scenes a cross-cultural comparison between Japan and the United States", Journal of Cross-cultural Psychology, Vol. 15 No. 1, pp. 79-93.

Nasar, J.L. (1987), "The effect of sign complexity and coherence on the perceived quality of retail scenes", Journal of the American Planning Association, Vol. 53 No. 4, pp. 499-509. Nasar, J.L. (1994), "Urban design aesthetics the evaluative qualities of building exteriors", Environment and Behavior, Vol. 26 No. 3, pp. 377-401.

Nasar, J.L. (2002), "What design for a presidential library? Complexity, typicality, order, and historical significance", Empirical Studies of the Arts, Vol. 20 No. 1, pp. 83-99.

Newman, A. J. (2007), “Uncovering dimensionality in the servicescape: Towards legibility”, The Service Industries Journal, Vol. 27 No.1,pp.15-28.

Orth, U.R. and Crouch, R.C. (2014), "Is Beauty in the Aisles of the Retailer? Package Processing in Visually Complex Contexts”, Journal of Retailing, Vol. 40 No. 4, pp. 524-537. 
Orth, U.R. and Wirtz, J. (2014), “Consumer processing of interior service environments: the interplay among visual complexity, processing fluency, and attractiveness”, Journal of Service Research, Vol. 17 No. 3, pp. 296-309.

Orth, U.R., Heinrich, F. and Malkewitz, K. (2012), "Servicescape interior design and consumers' personality impressions", Journal of Services Marketing, Vol. 26 No. 3, pp. 194203.

Palmer, J.F. (2000), "Reliability of rating visible landscape qualities", Landscape Journal, Vol. 19 No. 1-2, pp. 166-78.

Pals, R., Steg, L., Dontje, J., Siero, F. W., and van der Zee, K. I. (2014), "Physical features, coherence and positive outcomes of person-environment interactions: A virtual reality study", Journal of Environmental Psychology, Vol. 40 No. 3, pp. 108-116.

Pham, M.T., Cohen, J.B., Pracejus, J.W. and Hughes, G.D. (2001), “Affect monitoring and the primacy of feelings in judgment", Journal of Consumer Research, Vol. 28 No. 2, pp. $167-88$.

Prahalad, D. and Sawhney, R. (2011), Predictable Magic: Unleash the Power of Design Strategy to Transform your Business, Pearson Prentice Hall.

Purcell, T., Peron, E. and Berto, R. (2001), "Why do preferences differ between scene types?", Environment and Behavior, Vol. 33 No. 1, pp. 93-106.

Quartier, K., Christiaans, H. and Van Cleempoel, K. (2008), "Retail design: lighting as an atmospheric tool, creating experiences which influence consumers' mood and behaviour in commercial spaces", in: Undisciplined! Design research society conference 2008, Sheffield Hallam University, Sheffield, UK, 16-19 July 2008. 
Raajpoot, N.A., Sharma, A. and Chebat, J.-C. (2008), "The role of gender and work status in shopping center patronage", Journal of Business Research, Vol. 61 No. 8, pp. 825-33. Reber, R., Schwarz, N. and Winkielman, P. (2004), "Processing fluency and aesthetic pleasure: is beauty in the perceiver's processing experience?", Personality and Social Psychology Review, Vol. 8 No. 4, pp. 364-82.

Ringle, C.M., Sarstedt, M. and Mooi, E.A. (2010), "Response-based segmentation using finite mixture partial least squares", in Data Mining, Springer, US, pp. 19-49.

Rosen, D.E. and Purinton, E. (2004), “Website design: Viewing the web as a cognitive landscape", Journal of Business Research, Vol. 57 No. 7, pp. 787-94.

Rossiter J. R (2002). “The C-OAR-SE procedure for scale development in marketing”, Inter national Journal of Research in Marketing Vol.19 No. 4, pp: 1-31.

Roth, M. (2006), "Validating the use of Internet survey techniques in visual landscape assessment—an empirical study from Germany", Landscape and Urban Planning, Vol. 78 No. 3, pp. 179-92.

Roy, A. and Tai, S.T.C. (2003), "Store environment and shopping behavior: the role of imagery elaboration and shopping orientation", Journal of International Consumer Marketing, Vol. 15 No. 3, pp. 71-99.

Russell, J.A. and Pratt, G. (1980), “A description of the affective quality attributed to environments", Journal of Personality and Social Psychology, Vol. 38 No. 2, pp. 311-22. Scott, S.C. (1993), "Complexity and mystery as predictors of interior preferences", Journal of Interior Design, Vol. 19 No. 1, pp. 25-33. 
Shrive, F.M., Stuart, H., Quan, H. and Ghali, W.A. (2006), "Dealing with missing data in a multi-question depression scale: a comparison of imputation methods", BMC Medical Research Methodology, Vol. 6 No. 1, p. 57.

Singh, S.N., Dalal, N. and Spears, N. (2005), "Understanding web home page perception", European Journal of Information Systems, Vol. 14 No. 3, pp. 288-302.

Spies, K., Hesse, F. and Loesch, K. (1997), "Store atmosphere, mood and purchasing behavior", International Journal of Research in Marketing, Vol. 14 No. 1, pp. 1-17.

Stamps III, A.E. (2004), "Mystery, complexity, legibility and coherence: A meta-analysis", Journal of Environmental Psychology, Vol. 24 No. 1, pp. 1-16.

Stamps III, A.E. (2006), "Interior prospect and refuge", Perceptual and Motor Skills, Vol. 103 No. 3, pp. 643-53.

Stamps III, A.E. (2010), "Atmospheric permeability and perceived enclosure", Environment and Behavior, Vol. 44 No. 3, pp. 427-46.

Tang, I. C., Sullivan, W. C., and Chang, C. Y. (2015), "Perceptual evaluation of natural landscapes the role of the individual connection to nature", Environment and Behavior, Vol. 47 No. 6, pp. 595-617.

Tenenhaus, M., Vinzi, V.E., Chatelin, Y.-M. and Lauro, C. (2005), "PLS path modeling", Computational Statistics \& Data Analysis, Vol. 48 No. 1, pp. 159-205.

Tlauka, M. and Wilson, P.N. (1994), "The effect of landmarks on route-learning in a computer-simulated environment”, Journal of Environmental Psychology, Vol. 14, pp. 30513. 
Turley, L.W. and Milliman, R.E. (2000), "Atmospheric effects on shopping behavior: a review of the experimental evidence", Journal of Business Research, Vol. 49 No. 2, pp. 193211.

Tveit, M., Ode, Å. and Fry, G. (2006), "Key concepts in a framework for analysing visual landscape character", Landscape Research, Vol. 31 No. 3, pp. 229-55.

Tversky, B. (1993), “Cognitive maps, cognitive collages, and spatial mental models”, in Frank, A.U. and Campari, I. (Eds.), Spatial Information Theory: A Theoretical Basis for GIS, COSIT '93, Vol. 716, Lecture Notes in Computer Science, Springer, Berlin, pp. 14-24.

Ulrich, R.S. (1983), “Aesthetic and affective response to natural environment”, in: Altman, I. and Wohlwill, J.F. (Eds.), Human Behavior and Environment, Vol. 6, Plenum, New York, pp. $85-125$.

Ulrich, R.S. (1986). "Human responses to vegetation and landscapes", Landscape and Urban Planning, Vol. 3, pp. 29-44.

Vacker, B. (1993), "Beauty and the Beast (of advertising)", Advances in Consumer Research, Vol. 20 No. 1, pp. 345-51.

Veryzer, Jr, R.W. and Hutchinson, J.W. (1998), "The influence of unity and prototypicality on aesthetic responses to new product designs", Journal of Consumer Research, Vol. 24 No. 4, pp. $374-85$.

Vilnai-Yavetz, I., and Gilboa, S. (2010), “The effect of servicescape cleanliness on customer reactions", Services Marketing Quarterly, Vol. 31 No. 2, pp. 213-34.

Vilnai-Yavetz, I. and Rafaeli, A. (2006), “Aesthetics and professionalism of virtual servicescapes", Journal of Service Research, Vol. 8 No. 3, pp. 245-59. 
Voss, K.E., Spangenberg, E.R. and Grohmann, B. (2003), "Measuring the hedonic and utilitarian dimensions of consumer attitude", Journal of Marketing Research, Vol. 40 No. 3, pp. 310-20.

Wagner, J. (2000), "A model of aesthetic value in the servicescape." Handbook of Services Marketing and Management, pp. 69-85.

Walsh, V., Roy, R. and Bruce, M. (1988), "Competitive by design", Journal of Marketing Management, Vol. 4 No. 2, Vol. 201-16.

Wener, R.E., and Kaminoff, R.D. (1983), "Improving environmental information effects of signs on perceived crowding and behavior", Environment and Behavior, Vol. 15 No. 1, pp. $3-20$.

Wetzels, M., Odekerken-Schroder, G., and Van Oppen, C. (2009), "Using PLS path modeling for assessing hierarchical construct models: guidelines and empirical illustration”, $M I S$ Quarterly, Vol. 33 No. 1, pp. 177-95.

Wirtz, J. and Bateson, J.E.G. (1999), “Consumer satisfaction with services: integrating the environment perspective in services marketing into the traditional disconfirmation paradigm", Journal of Business Research, Vol. 44 No. 1, pp. 55-66. 
APPENDIX A: Images of a bank lobby with high and low levels of the various dimensions

(Images developed by the researcher by taking help from experts using 3D modelling and rendering software - Autodesk 3D Max and digital imaging software, Photoshop CS.)
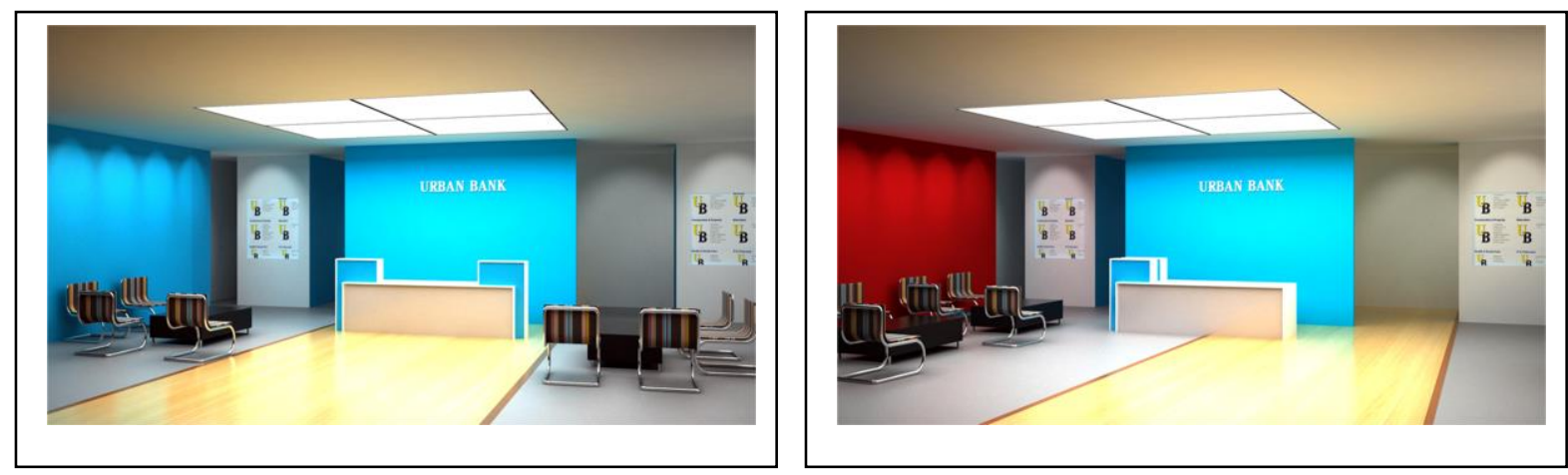

IMG-01- Coherence: high

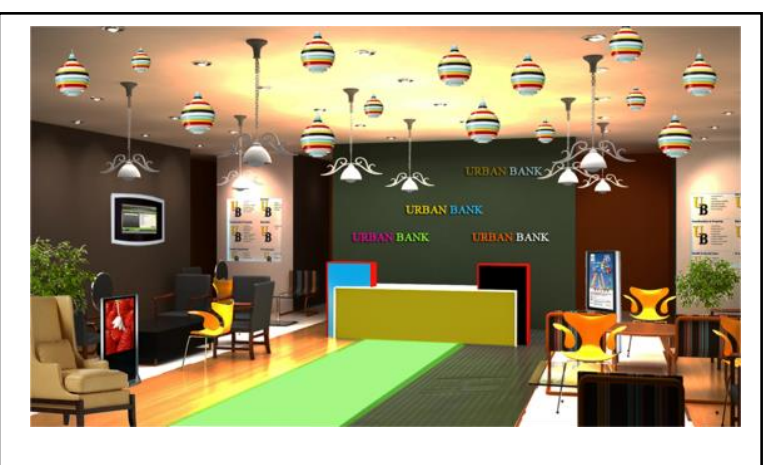

IMG-02- Coherence: low

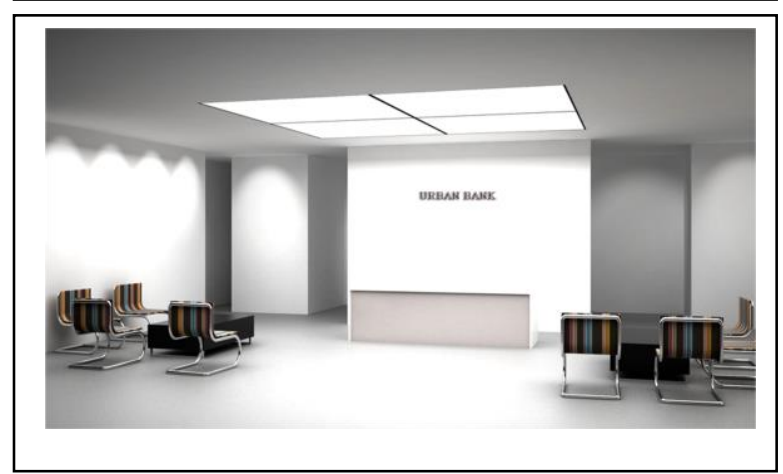

IMG-03- Complexity: high

IMG-04- Complexity: low
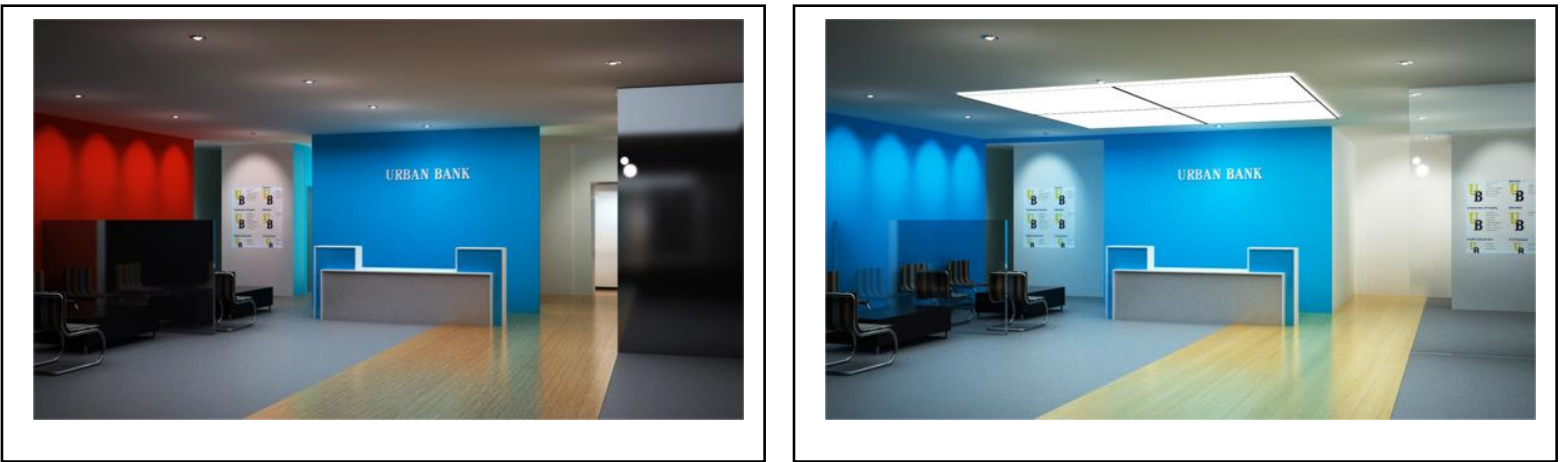

IMG-05- Mystery: high

IMG-06- Mystery: low 

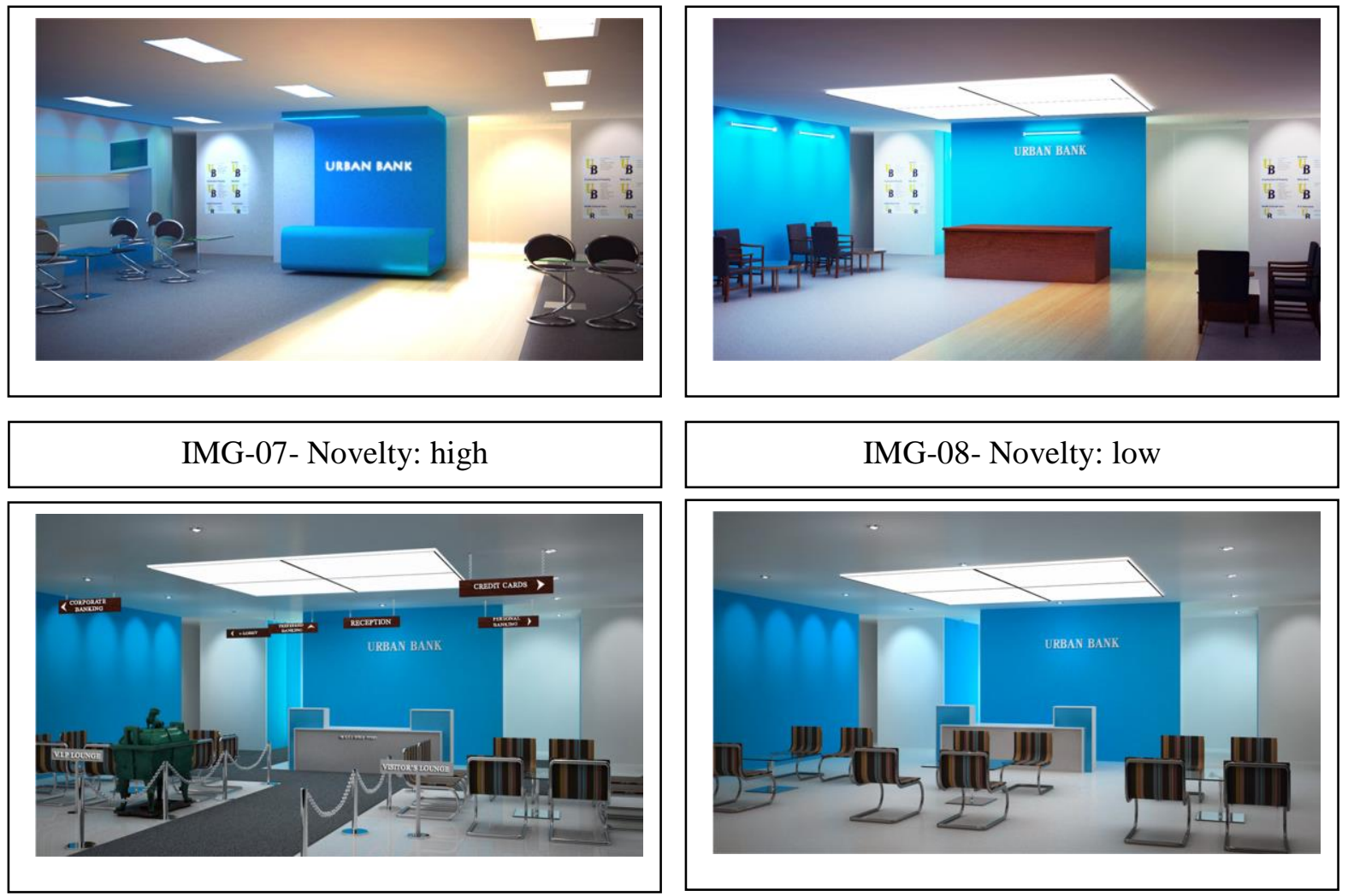

IMG-09- Legibility: high

IMG-10- Legibility: low 
APPENDIX B: Summary of scales

\begin{tabular}{ll}
\hline $\begin{array}{c}\text { Variables } \\
\text { (Types) } \\
\text { Legibility } \\
\text { (F) }\end{array}$ & \multicolumn{1}{c}{ Items } \\
& "The servicescape setting has good clarity of \\
& $\begin{array}{l}\text { layout or presence of signage which can } \\
\text { apparently assist finding your way around in } \\
\text { the setting". }\end{array}$ \\
& " "The servicescape setting contains some \\
& $\begin{array}{l}\text { landmarks which help to locate where you } \\
\text { are". } \\
\text { • }\end{array}$ \\
& "The servicescape has visible walkways to find \\
& your way around."
\end{tabular}

Reference

Dogu and Erkip (2000), Hanyu (2000), Herzog and Leverich (2003), Newman (2007)

Finlay et al. (2006), Hagerhall (2001), Hanyu (2000), Herzog and Bryce (2007), Stamps (2010), Palmer (1969)

Herzog et al. (1982), Finlay et al. (2006), Nasar (1987)

Cox and Cox (1994), Stamps (2004), Herzog and Leverich (2003), Herzog and Kropscott (2004)

- "The servicescape setting contains a lot of elements/noticeable features". 
Novelty

(F)

Preference

(R)

7-point

Likert scale.

Arousal/

Pleasure

(R)

7-point

Likert scale
- "The servicescape setting appears to be typical with other similar servicescapes I have seen".

- "The servicescape setting appears to be familiar to you".

- "The servicescape setting appears to be new to you".

- "I like this servicescape".

- "I prefer this servicescape over all other servicescape of this kind I have ever been/ seen".

- "This servicescape is my first choice".

- "I have an inclination to be part of this servicescape".

- P1 : Unhappy - Happy

- P2 : Annoyed - Pleased

- P3 : Dissatisfied - Satisfied

- P4 : Melancholic-Contented

- P5 : Despairing - Hopeful

- P6 : Bored - Relaxed

- P7 : Sluggish - Frenzied

- A1 : Dull - Jittery

- A2 : Un-aroused - Aroused

- A3 : Relaxed - Stimulated

- A4 : Calm - Excited

- A5 : Sleepy - Wide awake
Blythe (1999),

Cox and Cox (2002), Herzog and Stark (2004), Joseph-Mathews et al. (2009)

Herzog and Kutzli (2002), Ikemi (2005), Purcell et al. (2001)

Donovan et al. (1994)

\footnotetext{
Notes: $\mathrm{F}=$ formative measures; $\mathrm{R}=$ reflective measures
} 